\title{
Postnatal Neurogenesis and Gliogenesis in the Olfactory Bulb from NG2-Expressing Progenitors of the Subventricular Zone
}

\author{
Adan Aguirre and Vittorio Gallo \\ Center for Neuroscience Research, Children's Research Institute, Children's National Medical Center, Washington, DC 20010
}

We used a $2^{\prime}, 3^{\prime}$-cyclic nucleotide $3^{\prime}$-phosphodiesterase (CNP)- enhanced green fluorescent protein (EGFP) transgenic mouse to study postnatal subventricular zone (SVZ) progenitor fate, with a focus on the olfactory bulb (OB). The postnatal OB of the CNP-EGFP mouse contained $\mathrm{EGFP}^{+}$interneurons and oligodendrocytes. In the anterior SVZ, the majority of EGFP ${ }^{+}$progenitors were $\mathrm{NG}^{+}$. These $\mathrm{NG}^{+} / \mathrm{EGFP}^{+}$progenitors expressed the $\mathrm{OB}$ interneuron marker Er81, the neuroblast markers doublecortin (DC) and Distalless-related homeobox (DLX), or the oligodendrocyte progenitor marker Nkx2.2. In the rostral migratory stream (RMS), $\mathrm{EGFP}^{+}$cells displayed a migrating phenotype. A fraction of these cells were either NG2 ${ }^{-} / \mathrm{Er} 1^{+} / \mathrm{DC}^{+} / \mathrm{DLX}^{+}$or NG2 ${ }^{+} / \mathrm{Nkx} 2.2^{+}$. DiI $\left(1,1^{\prime}\right.$-dioctadecyl-3,3,3',3'tetramethylindocarbocyanine perchlorate) injection into the lateral ventricle (LV) of early postnatal mice demonstrated that $\mathrm{NG2}^{+}$/ $\mathrm{EGFP}^{+}$progenitors migrate from the SVZ through the RMS into the OB. Moreover, fluorescence-activated cell-sorting-purified NG2 ${ }^{+}$/ $\mathrm{CNP}^{-\mathrm{EGFP}^{+}}$or $\mathrm{NG}^{+} / \beta$-actin-enhanced yellow fluorescent protein-positive $\left(\mathrm{EYFP}^{+}\right)$progenitors transplanted into the early postnatal LV displayed extensive rostral and caudal migration. $\mathrm{EYFP}^{+}$or $\mathrm{EGFP}^{+}$graft-derived cells within the $\mathrm{RMS}$ were $\mathrm{DLX}{ }^{+} / \mathrm{Er} 81^{+}$ or Nkx2.2 $2^{+}$, migrated to the $\mathrm{OB}$, and differentiated to interneurons and oligodendrocytes. In the subcortical white matter (SCWM), grafted cells differentiated to either oligodendrocytes or astrocytes. Transplantation of NG2 ${ }^{+} / \mathrm{EYFP}^{+}$progenitors selectively purified from the SVZ showed that these cells were migratory and generated glia and neurons in the OB, hippocampus, and striatum. In contrast, cortical, $\mathrm{OB}$, or cerebellar NG2 ${ }^{+}$cells had a very limited migratory potential and gave rise to glia in the SCWM and striatum. Our findings indicate region-specific differences between $\mathrm{NG}^{+}$progenitor cells and show that $\mathrm{NG}^{+}$cells can migrate throughout the RMS and contribute to both gliogenesis and neurogenesis in the postnatal OB.

Key words: CNP-EGFP transgenic mice; neural progenitor; oligodendrocyte; interneuron; cell migration; rostral migratory stream

\section{Introduction}

The subventricular zone (SVZ) is a source of new neurons and glia throughout postnatal development into adulthood (Levison and Goldman, 1993; Doestch et al., 1999; Temple, 2001). Neural progenitors of the SVZ are mitotically active and are restricted to different cellular compartments specialized for distinct cell lineages (Levison and Goldman, 1993; Zerlin et al., 1995; Lim et al., 1997). The anterior SVZ (aSVZ) contains progenitor cells that migrate into the rostral migratory stream (RMS), to give rise to neurons in the olfactory bulb (OB) (Doetsch et al., 1999; Temple,

\footnotetext{
Received Aug. 30, 2004; revised 0ct. 11, 2004; accepted 0ct. 14, 2004.

This work was supported by National Institutes of Health (NIH) Grant R01NS045702 (V.G.), by the Wadsworth Foundation (V.G.), and by NIH-Mental Retardation and Developmental Disabilities Research Center Grant P3OHD40677. We are very grateful to Dr. L.-J. Chew for breeding and maintenance of the CNP-EGFP mice. We thank Dr. Tom Jessel (Columbia University, New York, NY) for the gift of the anti-Er81 antibody. We thank W. King (The William and Shirley Howard Hematopoetic Stem Cell Laboratory, Children's Research Institute, Children's Nationa Medical Center, Washington, DC) and Dr. R. Ruffner (Center for Microscopy and Image Analysis, George Washington University School of Medicine, Washington, DC) for assistance with fluorescence-activated cell sorting and acquisition of confocal images, respectively. We also thank Drs. S. Belachew, L.-J. Chew, T. Haydar, and D. Panchision for discussion and critical comments on this manuscript.

Correspondence should be addressed to Dr. Vittorio Gallo, Center for Neuroscience Research, Children's Research Institute, Children's National Medical Center, Washington, DC 20010. E-mail: vgallo@enmcresearch.org. DOI:10.1523/JNEUROSCI.3572-04.2004

Copyright $\odot 2004$ Society for Neuroscience $\quad 0270-6474 / 04 / 2410530-12 \$ 15.00 / 0$
}

2001; Coskun and Luskin, 2002; Carleton et al., 2003). Conversely, gliogenesis occurs predominantly from the posterior SVZ (Levison and Goldman, 1993; Goldman, 1995; Marshall and Goldman, 2002; Zerlin et al., 2004); it is not yet determined whether neural progenitors from the aSVZ can generate glial cells in the OB.

The combined use of retrovirus infection into the SVZ and time-lapse microscopy revealed distinct distribution and migration patterns for neuronal and glial precursors, and rostral migration of glial precursors was not observed (Suzuki and Goldman, 2003). In agreement with these findings, transplantation of SVZ cells into the lateral ventricle (LV) of perinatal mice demonstrated generation of neurons in the $\mathrm{OB}$ and oligodendrocytes in the subcortical white matter (SCWM), with no oligodendrogenesis occurring in the OB (Spassky et al., 2001). The same study concluded that oligodendrocytes in the $\mathrm{OB}$ originate from local progenitors that differentiate during forebrain development (Spassky et al., 2001).

In contrast to these findings, recent evidence indicates the existence of multipotent precursors in the RMS capable of giving rise to neurons, oligodendrocytes, and astrocytes (Gritti et al., 2002). These cells have the tendency to generate more oligodendrocytes than neurons or astrocytes (Gritti et al., 2002). Further- 
more, separate studies have shown that experimentally induced demyelination promotes the proliferation and mobilization of progenitors that populate the $\mathrm{OB}$ to generate mature oligodendrocytes (Nait-Oumesmar et al., 1999; Picard-Riera et al., 2002). Finally, polysialic acid (PSA)-neural cell adhesion molecule-positive $\left(\mathrm{NCAM}^{+}\right)$precursor cells transplanted into the LV of wild-type or shiverer mice displayed rostral migration and generated oligodendrocytes in the OB (Vitry et al., 2001).

The SVZ progenitor population that gives rise to OB interneurons has been characterized recently based on the expression of the ETS domain transcription factor Er81 and Distalless-related homeobox (DLX) proteins (Stenman et al., 2003). Expression of Er81 distinguishes these progenitors from a population of Islet ${ }^{+}$ precursors that are also present in the SVZ but give rise to striatal projection neurons (Stenman et al., 2003). The lineage relationship between the Er81 ${ }^{+}$neuronal progenitors and other precursors in the SVZ (Doetsch et al., 1999; Capela and Temple, 2002; Aguirre et al., 2004) is still undefined.

We have shown recently that cells expressing the proteoglycan NG2 represent a major multipotential progenitor population of the SVZ that gives rise to oligodendrocytes and interneurons (Belachew et al., 2003; Aguirre et al., 2004). In the present study, we investigated whether NG2-expressing cells of the SVZ also contribute to neurogenesis and oligodendrogenesis in the perinatal OB.

\section{Materials and Methods}

Transgenic mice. The 2',3'-cyclic nucleotide $3^{\prime}$-phosphodiesterase $(\mathrm{CNP})$-enhanced green fluorescent protein (EGFP) and $\beta$-actin-en-
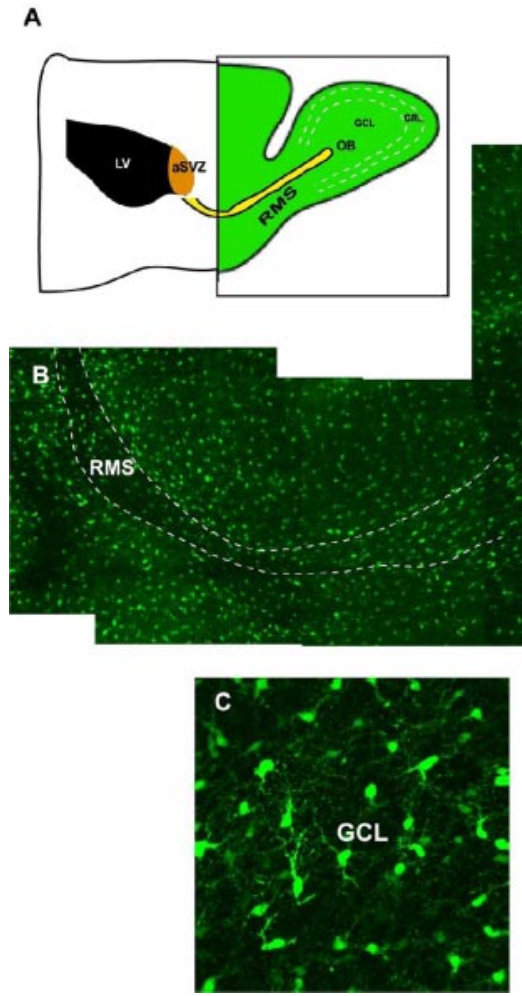

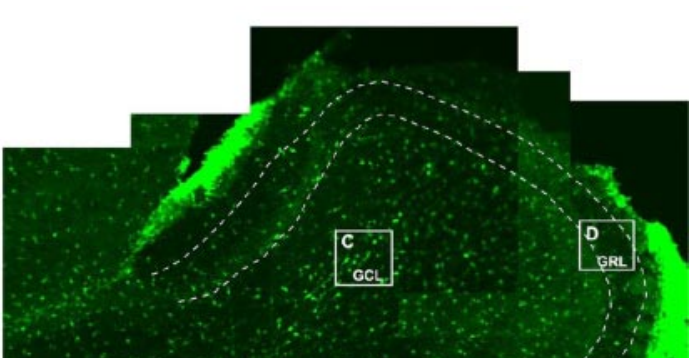

OB hanced yellow fluorescent protein (EYFP) transgenic mice (Tg ActbEYFP; stock number 003772; JAX Mice, Bar Harbor, ME) have been described previously (Yuan et al., 2002; Belachew et al., 2003; Aguirre et al., 2004). All animal procedures were performed according to the Institutional Animal Care and Use Committee, Children's National Medical Center, and National Institutes of Health guidelines.

Fluorescence-activated cell sorting. Brains were dissected out from postnatal day 2 (P2) to P4 CNP-EGFP mice or P2-P4 $\beta$-actin-EYFP mice and transferred to ice-cold HBSS (Invitrogen, San Diego, CA) containing 26 mM HEPES, $0.3 \%$ glucose, and $0.75 \%$ sucrose. Cells were dissociated in HBSS containing $0.1 \%$ trypsin and $100 \mathrm{U} / \mathrm{ml}$ DNase I (Sigma, St. Louis, MO) for $20 \mathrm{~min}$ at room temperature. The tissue was then transferred to HBSS containing $0.7 \mathrm{mg} / \mathrm{ml}$ trypsin inhibitor (Sigma) and triturated with a fire-polished Pasteur pipette. Cell suspensions were analyzed for light forward and side scatter using a FACStar Plus instrument (Beckton Dickinson, Franklin Lakes, NJ). For double NG2 ${ }^{+} / \mathrm{EGFP}^{+}$and $\mathrm{NG}^{+} / \mathrm{EYFP}^{+}$fluorescence-activated cell-sorting (FACS) analysis, cell suspensions were incubated with appropriate primary antibodies (see below) (Aguirre et al., 2004) and then with R-phycoerythrin (R-PE) conjugated secondary antibodies (Caltag, Burlingame, CA). For NG2 ${ }^{+}$ cell isolation from different brain areas, the SVZ, cortex, OB, and cerebellum were microdissected from $250-\mu$ m-thick coronal sections of P2-P4 brains, and cells were dissociated as described above.

Neurosphere preparation and differentiation. The SVZ was microdissected from $250-\mu \mathrm{m}$-thick coronal sections of P8 CNP-EGFP brains or $\beta$-actin-EYFP mice. Cells were cultured for the neural stem cell colonyforming (neurosphere) assay (Reynolds and Weiss, 1992; Aguirre et al., 2004). FACS-purified SVZ NG2 ${ }^{+} / \mathrm{EGFP}^{+}$or NG$^{+} / \mathrm{EYFP}^{+}$cells were seeded at a density of 10 viable cells/ $\mu$ l on uncoated 24 -well plates (BDFalcon, Franklin Lakes, NJ) and grown in stem cell medium (SCM) (Stem Cell Technologies, Vancouver, British Columbia, Canada) for $6 \mathrm{~d}$ in vitro (DIV) with a daily addition of $20 \mathrm{ng} / \mathrm{ml}$ epidermal growth factor (EGF; Upstate, Charlottesville, VA). Primary neurosphere colonies were subcloned by mechanical dissociation in SCM with EGF. Cells were replated at a density of 10 cells/ $\mu$ l on uncoated 24-well plates. Stem cell self-renewal was assessed after an additional 6 DIV. For differentiation experiments, single neurosphere colonies were transferred to individual wells of a 24-well culture plate precoated with $0.1 \mathrm{mg} / \mathrm{ml}$ D-polyornithine and laminin $(2 \mu \mathrm{g} / \mathrm{ml}$; Invitrogen) in SCM with $1 \% \mathrm{FBS}$ and $10 \mathrm{ng} / \mathrm{ml}$ BDNF (Upstate). Cells were processed by immunocytochemistry after 6 DIV (Aguirre et al., 2004).

Reverse transcription-PCR. RNA was isolated from P8 FACS-purified NG2 ${ }^{+} / \mathrm{EGFP}^{+}$cells or from neurospheres cultured for $4 \mathrm{~d}$ in differentiation medium using Trizol (Invitrogen). RNA (1 $\mu \mathrm{g}$ ) from each sample was reverse transcribed using the SuperScript First-Strand cDNA Synthesis kit (Invitrogen). The mouse gene-specific primers used were obtained from Integrated DNA Technologies (Coralville, IA). The sequences were as follows: Er81, sense 5'-CAGAGATCTGGCTCATGATTCAG-3', antisense 5'-AAAATGCAGCCTTCTGTTCTGC-3'; actin, sense 5'-CGTGGGCCGCCCTAGGCACCA-3', antisense 5'-AACATGCAGCCTTCTGTTCTGC-3'. Genes were amplified by denaturation at $94^{\circ} \mathrm{C}$ for $1 \mathrm{~min}$, annealing at $60^{\circ} \mathrm{C}$ for $1 \mathrm{~min}$, and extension at $72^{\circ} \mathrm{C}$ for $1 \mathrm{~min}$ for 35 cycles. PCR products were resolved by $1.2 \%$ agarose gel electrophoresis and visualized by ethidium bromide staining.

Immunocytochemistry. For cell sorting, cell suspensions were incubated with anti-NG2 antibody (1:1000; Chemicon, Temecula, CA) in DMEM (Invitrogen) plus 10\% FCS for 30 min at $4^{\circ} \mathrm{C}$. After three washes with DMEM, cells
Figure 1. EGFP ${ }^{+}$cells are present in the RMS and OB of the postnatal CNP-EGFP mouse. $A$, Schematic drawing of a parasagittal section of the postnatal mouse forebrain. The green-shaded area is shown in $B . B$, Confocal reconstruction of the RMS and OB from a parasagittal section obtained from a P8 CNP-EGFP mouse brain. A large number of EGFP ${ }^{+}$cells are present in the RMS and in the OB. C, D, High-magnification images obtained from the boxed areas in B. Note the higher density of EGFP ${ }^{+}$cells in the GCL than in the GRL. White dotted lines delineate the boundaries of the RMS and the boundaries between the GCL and GRL of the OB. Scale bars: $B, 300 \mu \mathrm{m} ; C, D, 50 \mu \mathrm{m}$. 
were incubated with the secondary antibody $\left(200 \mathrm{ng} / 10^{6}\right.$ cells; R-PE; Caltag) in $2 \mathrm{ml}$ of medium for $15 \mathrm{~min}$ at $4^{\circ} \mathrm{C}$. For immunocytochemistry, cell cultures were processed as described previously (Yuan et al., 2002; Aguirre et al., 2004) with the following primary antibodies, at a dilution of 1:500: anti-panDLX (from G. Panganiban, University of Wisconsin Madison, Madison, WI), TUJ1 (BabCo, Berkeley, CA), anti-GFAP (Sigma), and anti-GAD-67 rabbit polyclonal (Chemicon). Anti-O4 (mouse monoclonal IgM), anti-Er81 (provided by S. Morton and T. Jessel, Columbia University, New York, NY), and anti-GABA (Sigma) were used at a dilution of 1:50, 1:5000, and 1:1000, respectively.

Immunohistochemistry. Freshly cut, floating tissue sections $(50 \mu \mathrm{m})$ from P8 mice were prepared as described previously (Yuan et al., 2002; Aguirre et al., 2004). Primary antibody dilutions were as follows: 1:50 for anti-Nkx2.2 (Developmental Studies Hybridoma Bank, Hybridoma Bank, Iowa City, IA); 1:500 for anti-NG2 (Chemicon), anti-Ki67 (Novocastra, Newcastle, UK), anti-CNP and anti-MBP (Sternberger Monoclonal Incorporated, Lutherville, MD), anti-DLX (from G. Panganiban), anti-neuronal-specific nuclear protein (NeuN) (Chemicon), anti-GFP (Clontech), and anti-GFAP (Sigma); 1:1000 for anti-GAD-67 (Chemicon), anti-doublecortin (DC; Chemicon), and anti-nestin (Chemicon). Anti-Er81 (from S. Morton and T. Jessel) was used at a dilution of 1:5000.
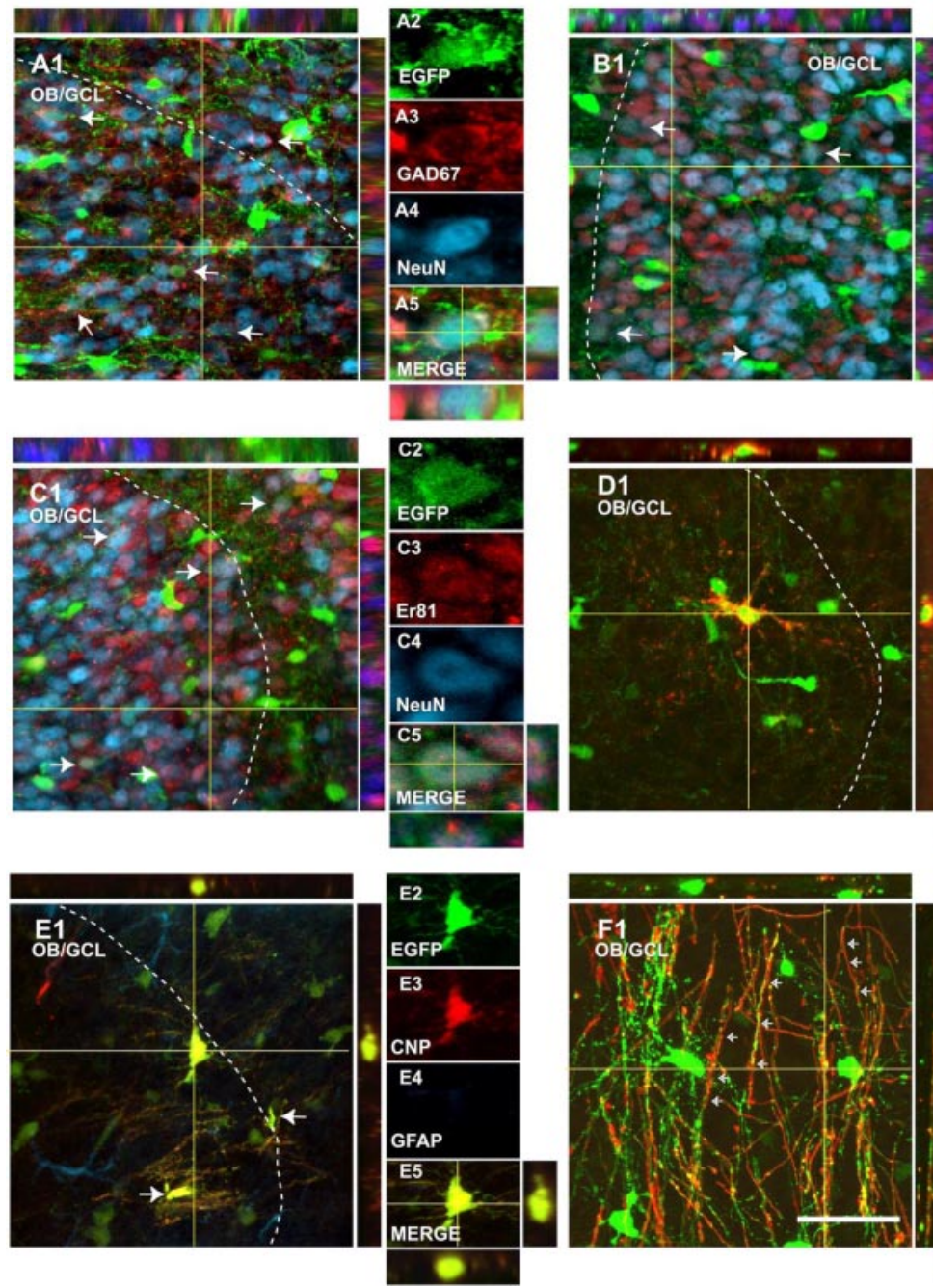

Figure 2. $\quad \mathrm{EGFP}^{+}$cells in the perinatal OB display neuronal and oligodendroglial phenotypes. Immunostaining of parasagittal sections from a P8CNP-EGFP mouse brain. A significant percentage of EGFP ${ }^{+}$cells expressed the mature neuronal marker NeuN $(A 4, B 4$, (4; blue) and the GABAergic interneuron markers GAD-67 (A3; red), DLX (B3; red), and Er81 (C3; red). A percentage of EGFP ${ }^{+}$cells expressed the oligodendrocyte markers 04 (D3; red), CNP (E3; red), and MBP (F3; red). White dotted lines delineate the boundaries between the GCL and GRL of the OB. Orthogonal reconstructions of confocal sections in the $z$-axes at the level indicated by the yellow lines are shown in $A 1, A 5, B 1, B 5, C 1, C 5, D 1, D 5, E 1, E 5, F 1$, and $F 4$. The individual cells selected for multi-marker illustration are indicated at the intersections of the yellow lines. The arrows represent double positive cells. Scale bar, $50 \mu \mathrm{m}$.
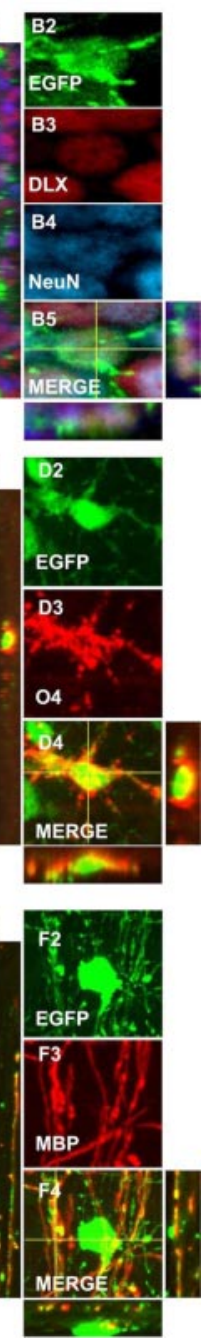

Injection of fluorescent tracer. To examine the migration of endogenous

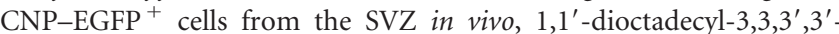
tetramethylindocarbocyanine perchlorate (DiI) $(1 \mathrm{mg} / \mathrm{ml}$ in $100 \%$ meth injected into the LV of P3-P4 mice. Glass micropipettes were backfilled was then analyzed by immunohistochemistry at $4 \mathrm{~d}, 1$ week, and 3 weeks

Transplantation and analysis of grafted cells. Wild-type P2-P4 FVB/ NxCB6 pups were used as recipients. FACS-purified NG2 ${ }^{+} / \mathrm{EGFP}^{+}$or (Aguirre et al., 2004). For experiments in which NG2 ${ }^{+}$cells were purified gration and anatomical distribution studies, mice were maintained for $4 \mathrm{~d}$ after the injection and processed for immunohistochemistry. For subsequent anatomical distribution and differentiation analyses of the grafted cells, mice were killed 2-4 weeks after the injection. Grafted $\mathrm{NG}^{+} / \mathrm{EGFP}^{+}$and $\mathrm{NG}^{+} / \mathrm{EYFP}^{+}$cells were readily visible under confocal microscopy in unstained tissue, using a $488 \mathrm{~nm}$ laser-line excitation. An anti-GFP rabbit polyclonal antibody (IgG; 1:500; BDClontech) was also used to confirm NG2 ${ }^{+}$cell differentiation by immunohistochemistry (Aguirre et al., 2004). In three different experiments, we quantified the percentage of total transplanted $\mathrm{EYFP}^{+}$cells found in the striatum, cortex, SCWM, RMS, hippocampus, and $\mathrm{OB}$. For analysis of cell differentiation 3 weeks after transplantation, NeuN, O4, and GFAP antibodies were used as cell markers to identify neurons, oligodendrocytes, and astrocytes, respectively. Ki67 antibody (1:500; Novocastra) was used to assess cell proliferation.

Microscopy and cell counting. A BX60 fluorescence inverted microscope (Olympus, Melville, $\mathrm{NY}$ ) was used to visualize immunofluorescence in cultured cells derived from neurospheres. Images were acquired using a $40 \times$ objective. For analysis in tissue sections, an MRC 1024 confocal laser-scanning microscope (Bio-Rad, Hercules, CA) equipped with a krypton-argon laser and an Olympus IX-70 inverted microscope were used to image localization of FITC (488 nm laser-line excitation; 522/35 emission filter), Texas Red (568 nm excitation; 605/32 emission filter), and Cy5 (647 excitation; $680 / 32$ emission filter). Optical sections ( $\mathrm{Z}=$ $0.5 \mu \mathrm{m})$ of confocal epifluorescence images were acquired sequentially using a $40 \times$ [numerical aperture (NA), 1.35], $60 \times(\mathrm{NA}, 1.40)$, or $100 \times(\mathrm{NA}, 1.35)$ oil objective with LaserSharp version 3.2 software (Bio-Rad). Confocal Assistant 4.02 and Image J (NIH) software were subsequently used to merge images and orthogonal studies, respectively. Merged images were processed in Photoshop 7.0 with minimal manipulations of contrast.

For cell counting in cultured cells, averages were obtained from three separate sets of cultures. A total of 20 clones per culture were counted. For cell counting of endogenous EGFP ${ }^{+}$cells in tissue sections, cells were counted in the SVZ and RMS of P8 mice. We found that $100 \%$ of the NG2 ${ }^{+}$ cells were also $\mathrm{EGFP}^{+}$. The analysis of the SVZ and RMS was performed at different rostral levels 
Table 1. Characterization of NG2 ${ }^{+}$cells in the aSVZ and RMS of the perinatal CNP-EGFP mouse

\begin{tabular}{|c|c|c|c|c|c|c|c|c|c|}
\hline & \multirow{2}{*}{$\begin{array}{l}\mathrm{EGFP}^{+} \\
\text {cells } / \mu \mathrm{m}^{3}\end{array}$} & \multicolumn{8}{|c|}{ Percentage of EGFP ${ }^{+}$cells } \\
\hline & & $\mathrm{NG}^{+} / \mathrm{DC}-$ & $\mathrm{NG} 2^{+} / \mathrm{DC}^{+}$ & $\mathrm{NG} 2^{-} / \mathrm{DC}^{+}$ & $\mathrm{NG} 2^{-} / \mathrm{DC}{ }^{-}$ & $\mathrm{NG2}{ }^{+} / \mathrm{Er} 81^{+}$ & $\mathrm{NG} 2^{+} / \mathrm{Nkx} 2.2^{+}$ & $\mathrm{Er}^{2} 1^{+} / \mathrm{DC} \mathrm{C}^{+}$ & 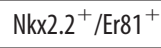 \\
\hline aSVZ & $3.1 \pm 0.4$ & $72.0 \pm 2.6$ & $10.1 \pm 1.4$ & $11.7 \pm 2.1$ & $16.7 \pm 4.4$ & $23.2 \pm 1.9$ & $42.2 \pm 1.7$ & $7.2 \pm 2.3$ & $3.7 \pm 2.0$ \\
\hline RMS & $4.6 \pm 0.7$ & $28.7 \pm 2.2$ & $1.1 \pm 0.4$ & $25.7 \pm 5.1$ & $45.7 \pm 6.2$ & $18.0 \pm 3.2$ & $66.0 \pm 4.4$ & $26.3 \pm 3.8$ & 0 \\
\hline
\end{tabular}

The analysis of the SVZ and RMS was performed at different rostral levels (Fig. 3, green boxes) in the CNP-EGFP mouse at P8. An average of three to four sections from three different brains ( $9-12$ sections total) were counted for the SVZ and RMS, respectively, to obtain an estimate of the total number of EGFP ${ }^{+}$cells. Percentages of EGFP ${ }^{+}$cells expressing NG2 proteoglycan, DC, Er81, and Nkx2.2 were estimated by scoring the number of cells double-labeled with the marker in question. Total EGFP+ cells counted ranged between 929 and 1108. Cell counting data in tissue sections are expressed as averages \pm SEM.

as shown in Figure 2. An average of three to four sections from three different brains (9-12 sections total) were counted for the SVZ and RMS, to obtain an estimate of the total number of $\mathrm{EGFP}^{+}$cells. The anatomical distribution of CNP-EGFP ${ }^{+}$cells was analyzed in $Z$-series confocal scanning images [20$30 \mu \mathrm{m}$ thickness; step size, $0.5 \mu \mathrm{m}$ between successive images of the same field $\left(228 \mu \mathrm{m}^{2}\right)$ ]. Percentages of EGFP ${ }^{+}$cells expressing different markers were then estimated by scoring the number of cells double-labeled with the markers in question. For counting of cells derived from transplanted wholebrain $\mathrm{NG}^{+} / \mathrm{EYFP}^{+}$cells, $\mathrm{EYFP}^{+}$cells were countedas described above in the granular cell layer (GCL) and glomerular layer (GRL) of the OB. Approximately 20-25 sections were counted for each OB to obtain an estimate of the total cells in the entire OB. Cell numbers were obtained from three different experiments (three brains total). Percentages of $\mathrm{EYFP}^{+}$cells expressing NeuN and O4 were estimated by scoring the number of cells double-labeled with the marker in question. For counting of cells derived from transplanted SVZ and cortical NG2 ${ }^{+} / \mathrm{EYFP}^{+}$ cells (see Fig. 9), EYFP $^{+}$cells were counted in different brain regions. Cell numbers were obtained by analyzing a total of 144 sections $(40 \mu \mathrm{m}$ thickness) from three different experiments (three different brains). Cell counting data in tissue sections were expressed as averages \pm SEM. Statistical analysis was performed by paired $t$ test.

\section{Results \\ EGFP $^{+}$cells in the perinatal OB display neuronal and oligodendroglial phenotypes}

The postnatal RMS and OB of the CNP-EGFP mouse contain a large number of $\mathrm{EGFP}^{+}$cells (Fig. $1 B-D$ ). In the $\mathrm{OB}$, these cells were present at a higher number in the GCL than in the GRL $\left(5.0 \pm 0.2\right.$ and $3.5 \pm 0.1$ cells $/ \mu \mathrm{m}^{3}$, respectively) (Fig. $\left.1 B-D\right)$. We characterized OB EGFP ${ }^{+}$cells with neuronal and glial markers. At P8, $34.7 \pm 3.4$ and $14.1 \pm 1.0 \%$ of the $\mathrm{EGFP}^{+}$cells were $\mathrm{NeuN}^{+}$in the GRL and GCL, respectively (Fig. $2 A$ ). Of these $\mathrm{EGFP}^{+} / \mathrm{NeuN}^{+}$neurons, $75.0 \pm 3.5$ and $70.4 \pm 3.7$ were GAD$67^{+}$in the GRL and GCL, respectively (Fig. $2 A$ ). Coexpression of $\mathrm{NeuN}$ and the transcription factors DLX (Fig. $2 B$ ) and Er81 (Fig. $2 C$ ) in virtually all of the $\mathrm{NeuN}^{+} / \mathrm{EGFP}^{+}$neurons confirmed an $\mathrm{OB}$ interneuron phenotype. Finally, the $\mathrm{OB} \mathrm{NeuN}^{-} / \mathrm{EGFP}^{+}$cells were stained with the oligodendrocyte-specific antibody $\mathrm{O} 4$ (Fig. $2 D$ ) and expressed the CNP and MBP proteins, markers for mature oligodendrocytes (Fig. 2E,F). These findings indicate that the postnatal OB of the CNP-EGFP mouse contains both $\mathrm{EGFP}^{+}$neurons and oligodendrocytes and raise the possibility that these cells might have originated from $\mathrm{EGFP}^{+}$progenitors migrating from the aSVZ through the RMS into the OB (Fig. 1B).

\section{$\mathrm{NG}^{+} / \mathrm{EGFP}^{+}$cells in the perinatal SVZ and RMS express markers of $\mathrm{OB}$ interneuron and oligodendrocyte progenitors We first characterized EGFP ${ }^{+}$cells in the P8 RMS by using anti- bodies for the RMS markers DC (Fig. $3 B, E, G$ ) and PSA-NCAM (data not shown) in parasagittal tissue sections. At P8, the EGFP ${ }^{+}$ cell density in the RMS was $4.6 \pm 0.7 / \mu \mathrm{m}^{3}$ (Table 1), and a significant percentage of these cells were $\mathrm{NG}^{+}{ }^{+}$(Fig. 3C1-C3, Table 1$) . \mathrm{NG}^{+} / \mathrm{EGFP}^{+}$and $\mathrm{NG}^{-} / \mathrm{EGFP}^{+}$cells in the RMS displayed the typical morphology of migrating cells (i.e., a small cell body with one or two short cell processes) (Fig. 3). In the}

RMS, a large percentage of the EGFP ${ }^{+}$cells coexpressed NG2 and the oligodendrocyte progenitor (OP) marker Nkx2.2 (Fig. 3D, Table 1) (Ericson et al., 1997). Virtually all of the $\mathrm{Nkx} 2.2^{+}$cells were $\mathrm{NG}^{+}$(Fig. 3D).

Based on the previous finding that $34 \%$ of the $\mathrm{NG}^{+} / \mathrm{EGFP}^{+}$ cells in the aSVZ expressed the neuroblast marker DLX (Aguirre et al., 2004), we further characterized the phenotype of the migrating NG2 ${ }^{+} / \mathrm{EGFP}^{+}$and NG2 ${ }^{-} / \mathrm{EGFP}^{+}$cells in the RMS with the OB interneuron marker Er81 and the neuroblast marker DC. We found that $\sim 1 \%$ of the total $\mathrm{EGFP}^{+}$cells in the RMS were $\mathrm{NG}^{+} / \mathrm{DC}^{+}$and $\sim 26 \%$ was $\mathrm{NG}^{-} / \mathrm{DC}^{+}$(Fig. $3 E$, Table 1 ). Consistent with these findings, we also observed that $18 \%$ of $\mathrm{EGFP}^{+}$cells in the RMS were $\mathrm{NG}^{+}{ }^{+}$and expressed the transcription factor Er81, which specifically labels progenitors of OB interneurons in the SVZ (Stenman et al., 2003) (Fig. 3F, Table 1). Moreover, we found that $\sim 26 \%$ of the EGFP ${ }^{+}$cells in the RMS coexpressed Er81 and DC (Fig. 3G, Table 1). We observed that virtually $100 \%$ of the Er $81^{+} / \mathrm{EGFP}^{+}$cells in the RMS were also $\mathrm{DLX}^{+}$(data not shown). Importantly, coexpression of Nkx2.2 and Er81 in RMS EGFP ${ }^{+}$cells was never observed. These data indicate that $\mathrm{EGFP}^{+}$cells in the RMS express both OB interneuron and $\mathrm{OP}$ markers.

In the aSVZ, $\sim 10 \%$ of the $\mathrm{EGFP}^{+}$cells were $\mathrm{NG}^{+} / \mathrm{DC}^{+}$ (Fig. $3 H$, Table 1 ) and $23 \%$ were $\mathrm{NG2}^{+} / \mathrm{Er}^{2} 1^{+}$(Fig. 3I, Table 1). Er81 expression in SVZ NG2 ${ }^{+} / \mathrm{EGFP}^{+}$cells was confirmed by reverse transcription (RT)-PCR in FACS-purified P8 cells (see Fig. 5I). In the aSVZ, $\sim 40 \%$ of the $\mathrm{NG}^{+} / \mathrm{EGFP}^{+}$cells expressed $\mathrm{Nkx} 2.2$ (Table 1); however, only $3 \%$ of EGFP ${ }^{+}$cells coexpressed Nkx 2.2 and Er81 (Table 1).

All of these data obtained in the RMS and aSVZ indicate that EGFP $^{+}$cells express both OB interneuron and OP markers. Our results suggest that aSVZ NG2 ${ }^{+} / \mathrm{EGFP}^{+}$progenitors that express Er81 and DC might migrate rostrally into the RMS and downregulate NG2 expression while they differentiate intoEGFP ${ }^{+} \mathrm{OB}$ interneurons. Furthermore, our analysis also indicates that $\mathrm{NG}^{+}{ }^{+} / \mathrm{EGFP}^{+}$progenitors that express NKx2.2 maintain NG2 expression in the RMS and that these progenitors might generate $\mathrm{EGFP}^{+}$oligodendrocytes in the OB.

\section{$\mathrm{NG}^{+} / \mathrm{EGFP}^{+}$cells in the perinatal SVZ migrate to the $\mathrm{OB}$}

To directly demonstrate that $\mathrm{NG}^{+} / \mathrm{EGFP}^{+}$progenitors migrate from the SVZ through the RMS into the OB, we first injected DiI into the LV of P3 mice and characterized the DiI-labeled cells $4 \mathrm{~d}$ after the injection. Figure 4 shows that many $\mathrm{EGFP}^{+}$cells that incorporated DiI were found migrating throughout the entire RMS $4 \mathrm{~d}$ after the injection (Fig. $4 A-D, F, G$ ). At this time, a few $\mathrm{DiI}^{+} / \mathrm{EGFP}^{+}$cells were also found in the OB (Fig. $4 E$ ). We further characterized the phenotype of $\mathrm{DiI}^{+} / \mathrm{EGFP}^{+}$cells and found that substantial numbers of the cells expressed NG2 (Fig. $4 F$ ) or DC (Fig. $4 G$ ).

Additional analysis of the brains at $4 \mathrm{~d}$ after the DiI injection confirmed the accuracy of our LV injection protocol, because we were also able to demonstrate the previously described (Suzuki 

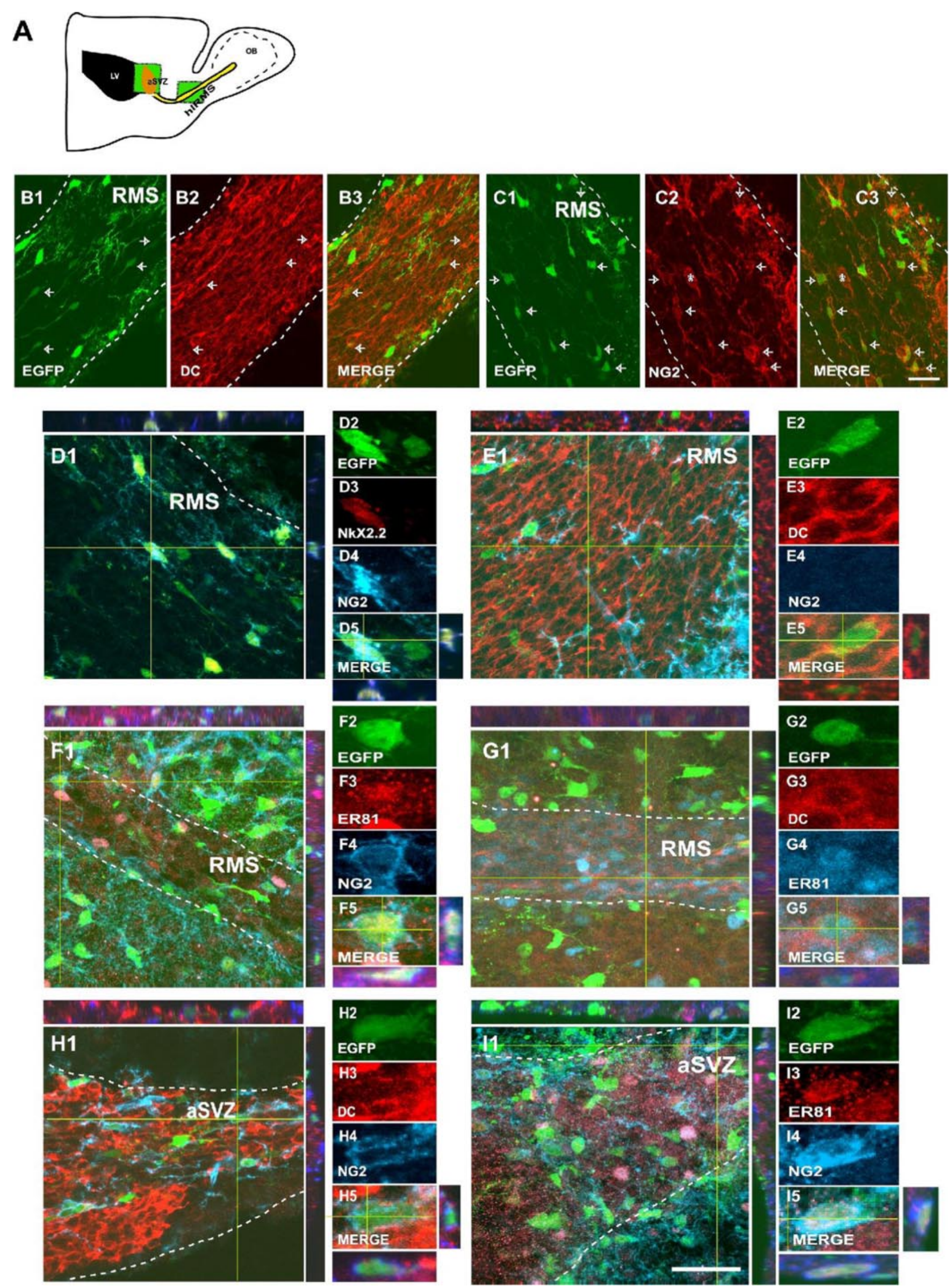

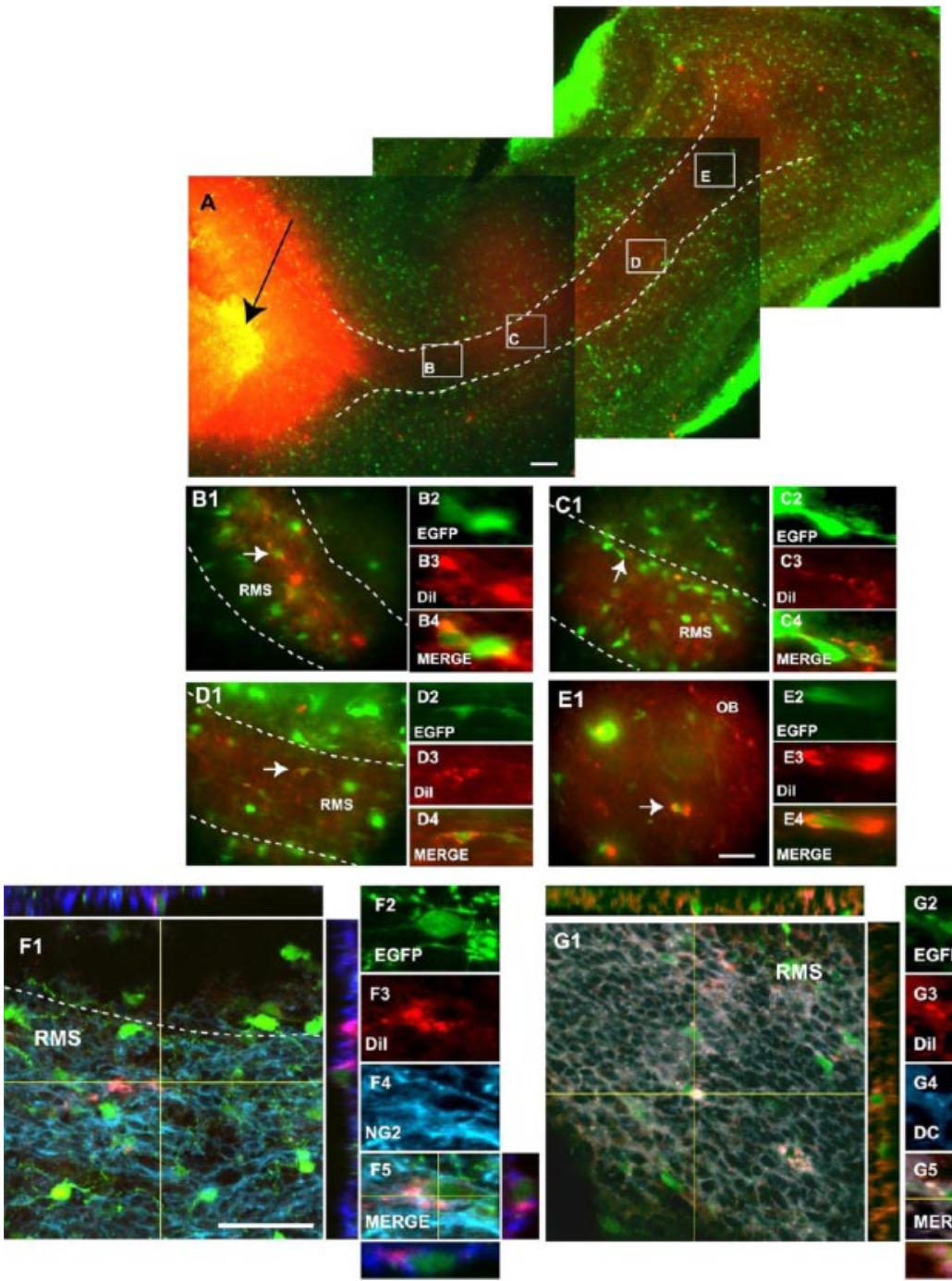

Figure 4. $\quad \mathrm{NG}^{+}$cells migrate from the SVZinto the RMS. A-E, Reconstruction of a parasagittal brain section of a P8 CNP-EGFP mouse $4 \mathrm{~d}$ after Dil injection into the LV (black arrow). EGFP+ ${ }^{+}$cells were found throughout the entire RMS and displayed morphologies of migratory cells. $B-D$, At this time, a small percentage of $\mathrm{Dil}^{+} / \mathrm{EGFP}^{+}$(red/green) cells were also found in the $0 \mathrm{~B}$ $(E)$. Boxes in $A(B-E)$ are shown at a higher magnification, and individual $\mathrm{Dil}^{+} / \mathrm{EGFP}^{+}$-labeled cells (white arrows) are also displayed at a higher magnification. F, G, A percentage of the migrating $\mathrm{Dil}^{+} / \mathrm{EGFP}^{+}$cells express NG2 (F4; blue) and DC (G4; blue). White dotted lines represent RMS boundaries. Orthogonal reconstructions of confocal sections in the $z$-axes at the level indicated by the yellow lines are shown in $F 1, F 5, G 1$, and $G 5$. The individual cells selected for multi-marker illustration are indicated at the intersections of the yellow lines. Scale bars: $A, 300 \mu \mathrm{m} ; B-G, 50 \mu \mathrm{m}$.

and Goldman, 2003) caudal migration of glial progenitors from the SVZ into the SCWM. Supplemental Fig. S1 (available at www. jneurosci.org

as supplemental material) shows that a large number of $\mathrm{DiI}^{+} /$ EGFP $^{+}$cells were found distributed throughout the entire SCWM (Fig. S1 A-D). Importantly, most of these $\mathrm{DiI}^{+} / \mathrm{EGFP}^{+}$

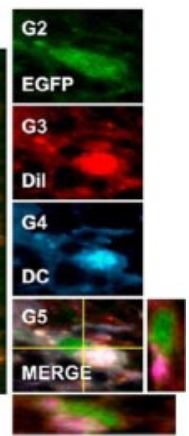

cells maintained NG2 immunoreactivity or were labeled with $\mathrm{O} 4$ antibodies, indicating a glial fate (Fig. $\mathrm{S} 1 E, F)$.

\section{$\mathrm{NG}^{+}$cells purified from the $\mathrm{SVZ}$ are multipotent and generate $\mathrm{OB}$ interneurons and oligodendrocytes in vitro}

To define the lineage potential of aSVZ $\mathrm{NG}^{+}$cells, we generated neurosphere cultures from purified SVZ NG2 ${ }^{+}$cells and characterized their progeny in vitro. Our previous reports indicate that total brain $\mathrm{NG} 2^{+}$cells form neuropheres and behave as multipotent neural stem cells in vitro (Belachew et al., 2003; Aguirre et al., 2004). Using P8 striatal-SVZ NG2 ${ }^{+}$/ $\mathrm{EGFP}^{+}$or NG2 ${ }^{+} / \mathrm{EYFP}^{+}$(purified from a $\beta$-actin tgEYFP transgenic mouse; stock number 003772; JAX Mice) cells seeded at a clonal density, we observed neurosphere formation after 7 DIV (Aguirre et al., 2004) (data not shown). Dissociation of individual spheres into single cells and replating gave rise to secondary neurospheres, which could then be repassaged several times and frozen, indicating selfrenewal (Aguirre et al., 2004) (data not shown).

Secondary and tertiary neurospheres were plated under differentiating conditions to characterize the $\mathrm{NG}^{+}$cellderived progeny. We observed that, similar to $\mathrm{NG}^{+} / \mathrm{EGFP}^{+}$cells (Aguirre et al., 2004), striatal-SVZ NG2 ${ }^{+} / \mathrm{EYFP}^{+}$(Fig. $5 A-D)$ cells were also multipotent. Both types of FACS-purified NG2 ${ }^{+}$cell populations gave rise to a similar progeny [i.e., $12-16 \% \quad \beta$-tubulin ${ }^{+}\left(\mathrm{TUJ1}^{+}\right)$neurons, $5-8 \% \mathrm{O}^{+}{ }^{+}$immature oligodendrocytes, and $\sim 50 \% \mathrm{GFAP}^{+}$astrocytes (Belachew et al., 2003) ]. Furthermore, NG2 ${ }^{+} / \mathrm{EYFP}^{+}$ and $\mathrm{NG}_{2}{ }^{+} / \mathrm{EGFP}^{+}$cell-derived neurospheres comprised $\mathrm{OB}$ interneurons, identified with anti-GABA (Fig. 5E3,F3), antiGAD-67 (Fig. 5C3,G4), anti-DLX (Fig. 5F4), and anti-Er81 (Fig. 5D3,E4,G3,H3) antibodies. We found that the entire population of $\mathrm{GABA}^{+}$cells was also $\mathrm{DLX}^{+}$(Fig. $5 F$ ) and that a large percentage of $\mathrm{GABA}^{+}$ cells also expressed Er81 (Fig. 5E). To quantify the percentage of Er81 ${ }^{+} \mathrm{OB}$ interneurons generated from SVZ NG2 ${ }^{+}$cells, we performed double immunolabeling with anti- $\beta$-tubulin (TUJ1

Figure 3. $\mathrm{NG2}{ }^{+}$cells in the SVZ and RMS express markers for neuronal progenitors and OPs. A, Schematic drawing of a parasagittal section of the postnatal mouse forebrain. The green boxes represent the areas selected for cell imaging and cell counting in the aSVZ and horizontal limb of the RMS (hIRMS). B1-B3, EGFP ${ }^{+}$cells (green) are found in the hIRMS. The RMS was labeled with anti-DC (red). C1-C3, NG2 immunostaining (red) of the RMS demonstrates the presence of NG2 ${ }^{+}$progenitors in this structure. Arrows represent double positive cells, and the asterisks in $C 2$ and $C 3$ represent a blood vessel. D1-D5, A percentage of the NG2 ${ }^{+}$progenitors in the RMS (D4; blue) express the OP marker Nkx2.2 (D3; red). E1-E5, F1-F5, A percentage of EGFP ${ }^{+} / \mathrm{NG2}{ }^{-}$cells (green/blue) express DC (E3; red) in the RMS. A percentage of the EGFP ${ }^{+}$cells were NG2 ${ }^{+}$(F4; blue) and Er81 ${ }^{+}$(F3; red) in the RMS. G1-G5, A population of EGFP ${ }^{+}$cells in the horizontal limb of the RMS coexpress DC (G3; red) and Er81 (G4; blue), markers for OB interneurons. H1-H5, I1-I5, A percentage of NG2 ${ }^{+} /$EGFP $^{+}$cells in the aSVZ express DC (H3; red) and Er81 (I3; red). White dotted lines delineate the boundaries of the RMS. Orthogonal reconstructions of confocal sections in the $Z$-axes at the level indicated by the yellow lines are shown in $E 1, E 5, F 1, F 5, G 1, G 5, H 1, H 5, I 1$, and 15. The individual cells selected for multi-marker illustration are indicated at the intersections of the yellow lines. Scale bar, $50 \mu \mathrm{m}$. 
clone) and Er81 antibodies. We observed that $83.8 \pm 1.6$ of the $\beta$-tubulin ${ }^{+}$cells were also Er81 ${ }^{+}$(Fig. 5D,H). Finally, expression of the Er81 gene in the progeny of $\mathrm{NG}^{+}{ }^{+}$cells was confirmed by RT-PCR of mRNA purified from NG2 ${ }^{+} / \mathrm{EGFP}^{+}$cellderived neurospheres (Fig. 5I).

Grafted NG2 ${ }^{+}$cells migrate through the RMS and give rise to interneurons and oligodendrocytes in the $\mathrm{OB}$

To define the lineage potential of $\mathrm{NG}^{+}$ cells in the $\mathrm{OB}$ in vivo, we grafted early postnatal (P2-P4) $\mathrm{NG}^{+} / \mathrm{EYFP}^{+}$and $\mathrm{NG}^{+} / \mathrm{EGFP}^{+}$cells FACS purified from total brain (Aguirre et al., 2004) into the LV of P3-P4 wild-type mice. After transplantation $(24-48 \mathrm{hr}), \mathrm{EYFP}^{+}$cells were seen attached to the wall of the LV, and a small percentage were found in the RMS, although none were seen in the $\mathrm{OB}$ (data not shown). Four days after transplantation (4 DAT), $12.0 \pm 2.0 \%(n=2960$ cells $)$ of the grafted EYFP ${ }^{+}$cells found in the aSVZ and RMS still coexpressed nestin and Ki67 ( $n=350$ and 329 cells, respectively) (data not shown), indicative of an undifferentiated and proliferative state. At the same age, grafted $\mathrm{NG}_{2}{ }^{+} / \mathrm{EYFP}^{+}$cells displayed a widespread migratory pattern in the brain (data not shown). $\mathrm{EYFP}^{+}$cells were predominantly incorporated in the SCWM, striatum, hippocampus, fimbria, and $\mathrm{OB}$ (see Fig. 9) (data not shown). Migration and differentiation of $\mathrm{NG}_{2}{ }^{+}$cells in the hippocampus after transplantation has been characterized previously (Aguirre et al., 2004). We focused the present study on the RMS and OB.

At 4 DAT, $\mathrm{EYFP}^{+}$cells could be found throughout the entire RMS (Fig. 6A1), and a significant percentage displayed a typical migrating morphology (Figs. 6A2, $7 B 1, B 2$, arrows). At this time, a small percentage of grafted cells had reached the $\mathrm{OB}$ (Fig. 6B1,B2) but maintained the morphology of migratory cells and a nondifferentiated phenotype. Three weeks after transplantation (3 WAT), $18.0 \pm 4.1 \%$ ( $n=450$ cells $)$ of the total grafted $\mathrm{EYFP}^{+}$ cells were present in the $\mathrm{OB}$ and were found distributed in different regions (Fig. 6B3-B6), including the GCL (Fig. 6B3B6) and the GRL (Fig. 6B4). Importantly, grafted $\mathrm{EYFP}^{+}$cells found in the $\mathrm{OB}$ at this time displayed different morphologies; a significant percentage had a typical neuronal morphology (small cell body and long cell processes) (Fig. 6B3-B6, arrows), whereas a higher percentage of cells exhibited a larger cell body and a more complex array of cellular processes, typical of mature oligodendrodocytes (Fig. $6 B 4, B 6$, arrowheads).

We then wanted to characterize the phenotype of the migrat-
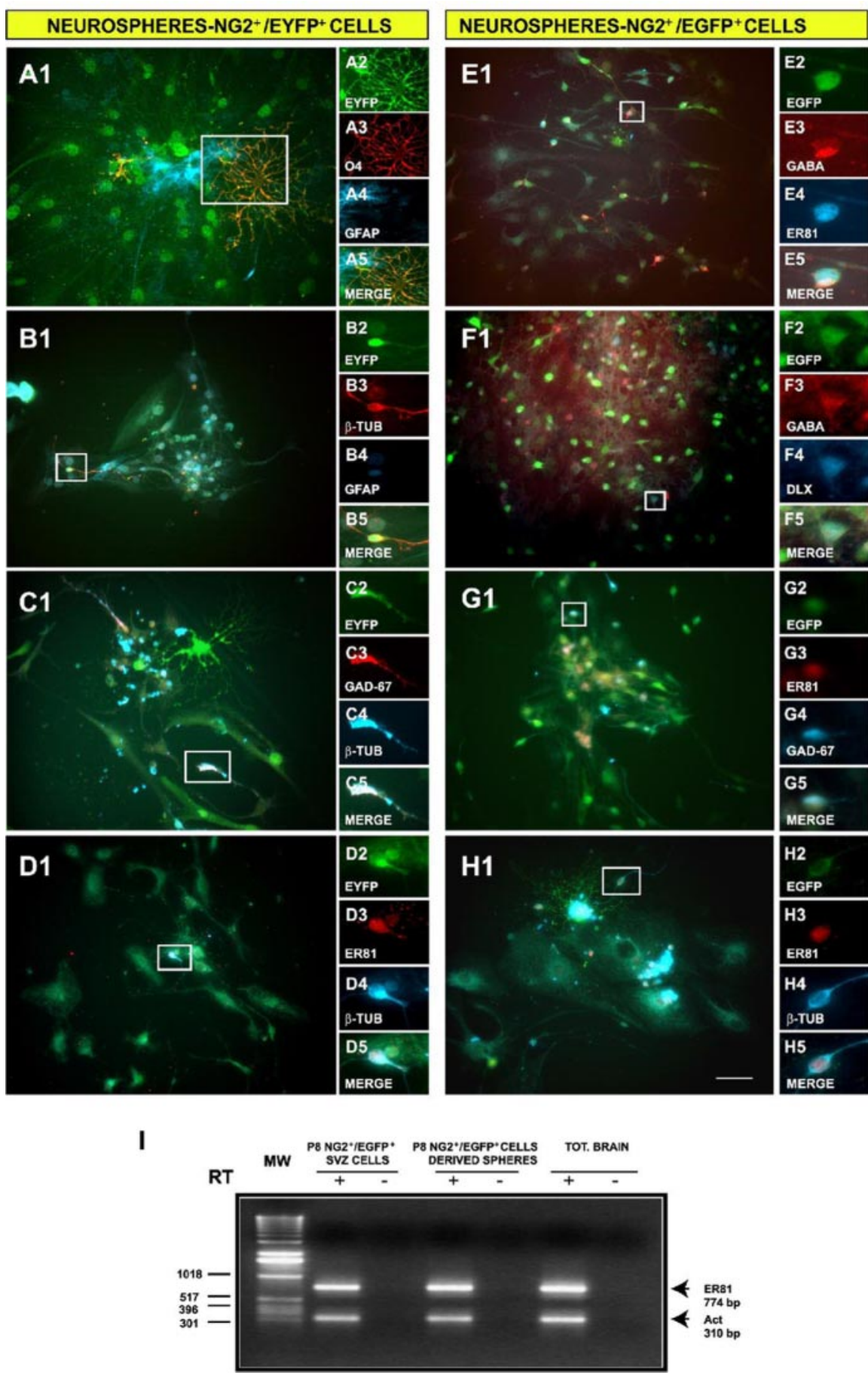

Figure 5. $\mathrm{NG2}^{+}$cells purified from the SVZ generate $\mathrm{OB}$ interneurons and oligodendrocytes in vitro. Neurospheres were generated from NG2 ${ }^{+} / \mathrm{EGFP}^{+}$and NG2 ${ }^{+} /$EYFP $^{+}$progenitors FACS purified from the SVZ. After plating at a clonal dilution, cells were allowed to differentiate for 6 DIV. $A-D$, Indirect immunofluorescence analysis of their progeny indicated that NG2 ${ }^{+} /$EYFP $^{+}$ cells are multipotent. Oligodendrodrocytes, astrocytes, and neurons were identified by 04 ( $A 3$; red), GFAP ( $A 4$, B4; blue), and TUJ1 ( $B 3$, red; $\left(4, D 4\right.$, blue) antibodies, respectively. $C-H, O B$ interneurons were identified in NG2 ${ }^{+} / \mathrm{EYFP}^{+}(C, D)$ and in $\mathrm{NG2}^{+} /$ $\operatorname{EGFP}^{+}(E-H)$ neurospheres using anti-GAD-67 (C3, red; G4, blue), anti-Er81 (D3, G3, H3, red; E4, blue), anti-Dlx (F4; blue), and anti-GABA (E3, F3; red) antibodies. I, The transcription factor Er81 is expressed in postnatal (P8) SVZ NG2 ${ }^{+} /$EGFP $^{+}$cells (lane 2) and NG2 ${ }^{+} / \mathrm{EGFP}^{+}$-derived neurospheres (lane 4), as shown by RT-PCR. - , RNA that was not reverse transcribed was used as a negative control. Scale bar, $50 \mu \mathrm{m}$. ing $\mathrm{EYFP}^{+}$cells in the RMS. EYFP ${ }^{+}$cells in the RMS were mostly unipolar or bipolar (Fig. 7B1,B2, arrows), but we also observed multipolar morphologies (Fig. 7B1,B3, arrowheads). All graftderived unipolar/bipolar $\mathrm{EYFP}^{+}$cells in the RMS were $\mathrm{DC}^{+}$(Fig. 7C). These $\mathrm{EYFP}^{+} / \mathrm{DC}^{+}$cells also expressed early markers of $\mathrm{OB}$ 

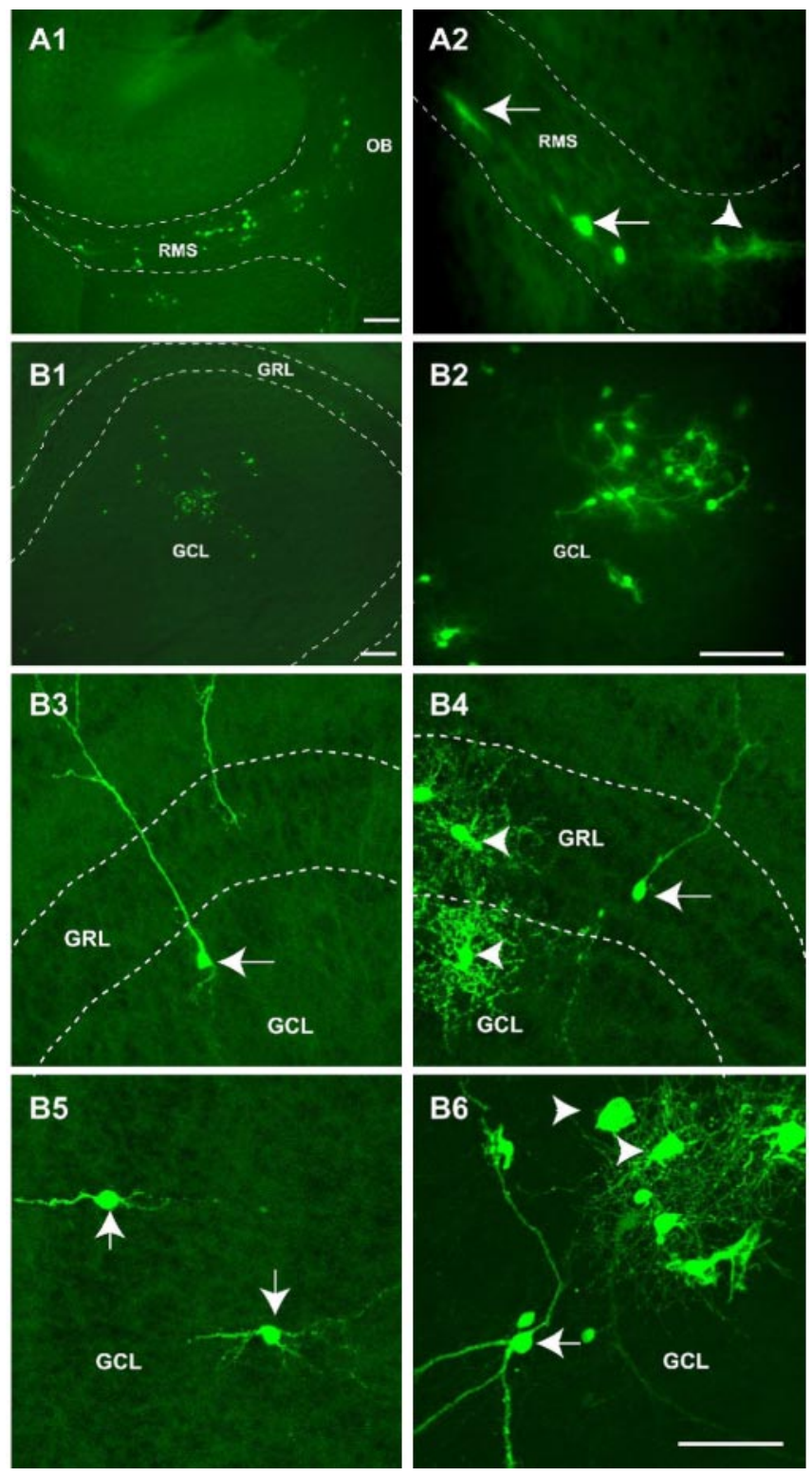

Figure 6. Grafted NG2 ${ }^{+} / \mathrm{EYFP}^{+}$cells migrate rostrally into the RMS to populate the $\mathrm{OB} . A_{\text {, }}$ $B, \mathrm{NG}^{+} /{ }^{+}$EYFP ${ }^{+}$cells were FACS purified from $\mathrm{P} 3$ brains and transplanted in the LV of $\mathrm{P} 3$ wild-type host mice. Brains were analyzed at 4 DAT $(A 1, A 2)$ and 3 WAT $(B 1-B 6)$. EYFP ${ }^{+}$cells were visualized by fluorescence microscopy. $A 1, A 2$, Migrating EYFP ${ }^{+}$cells were observed as early as 4 DAT throughout the RMS. B1-B6, At 3 WAT, EYFP ${ }^{+}$cells were found in the $0 B$ and displayed morphological features of neurons (arrows) and oligodendrocytes (arrowheads). These cells were observed both in the GRL and in the GCL. Dotted lines depict the RMS and the $G C L$ of the $O B$ in $A 1$ and $A 2$ and in $B 1, B 3$, and $B 4$, respectively. Scale bars: $A 1, B 1,300 \mu \mathrm{m} ; A 2$, $B 2,200 \mu \mathrm{m} ; B 3-B 6,50 \mu \mathrm{m}$.

interneurons, including DLX (Fig. 7D) and Er81 (data not shown), but were $\mathrm{NG}^{-}$. A fraction of graft-derived $\mathrm{EYFP}^{+}$cells were $\mathrm{NG}^{+}{ }^{+}$(Fig. $7 E$ ) and/or O4 ${ }^{+}$(Fig. $7 F$ ) but did not express DC (Fig. 7E) (data not shown). These cells were mostly multipolar (Fig. $7 E, F)$ and expressed Nkx2.2 (data not shown). These results indicate that graft-derived $\mathrm{EYFP}^{+}$cells migrating throughout the RMS are both committed neuronal and committed oligodendrocyte precursors.

At 3 WAT, we found that $8.0 \pm 2.1 \%$ of the $\mathrm{EYFP}^{+}$cells in the OB expressed Ki67 ( $n=208$ cells) (Fig. 8A,B), indicating that a small percentage of the grafted cells were still proliferative in the OB. To further characterize the fate of the grafted EYFP ${ }^{+}$cells in the $\mathrm{OB}$, we performed immunolabeling with several neuronal and glial markers. At 3 WAT, a total of $29 \%$ of the EYFP ${ }^{+}$cells were neurons, as identified by NeuN staining (Fig. 8C, Table 2). These neurons were distributed both in the GCL (19\%) and in the GRL (10\%) (Table 2). Interestingly, $57 \%$ of the total EYFP ${ }^{+}$ grafted cells displayed the oligodendrocyte marker O4 (Fig. 8G, Table 2 ), and $\sim 30 \%$ of the $\mathrm{EYFP}^{+}$cells expressed markers for differentiated oligodendrocytes, such as CNP (Fig. $8 H$ ) and MBP (data not shown). Oligodendrocytes were found predominantly in the GCL (52\%), and only a small percentage (5\%) were found in the GRL (Table 2).

The $\mathrm{NG}_{2}{ }^{+}$cell-derived neurons in the OB were interneurons, as demonstrated by GAD-67 expression in virtually $100 \%$ of the $\mathrm{NeuN}^{+} / \mathrm{EYFP}^{+}$cells found in the OB (Fig. 8D). Importantly, graft-derived neurons in the OB maintained expression of DLX (Fig. $8 E$ ) and Er81 (Fig. $8 F$ ). We never found EYFP ${ }^{+}$cells in the OB that expressed the astroglial marker GFAP.

Transplantation of $\mathrm{NG}^{+} / \mathrm{EGFP}^{+}$cells isolated from the CNP-EGFP mouse yielded results that were similar to those obtained with $\mathrm{NG}_{2}{ }^{+} / \mathrm{EYFP}^{+}$cells (supplemental Fig. S2, available at www.jneurosci.org as supplemental material). At 4 DAT, $\mathrm{NG}^{+} / \mathrm{EGFP}^{+}$cells were seen migrating throughout the RMS (supplemental Fig. S2 B1,B2; available at www.jneurosci.org as supplemental material), and 1 week after transplantation, $\mathrm{EGFP}^{+}$cells were found in both the GCL and the GRL of the OB (supplementary Fig. S2E,F; available at www.jneurosci.org as supplemental material). A significant percentage of these grafted cells were interneurons, because they expressed DC (Fig. S2 E3,F3; available at www.jneurosci.org as supplemental material), DLX (Fig. S2 F4), and Er81 (data not shown).

$\mathrm{NG} 2{ }^{+}$cell-derived progenies were also found in the SCWM as a consequence of caudal migration to this brain area. At 3 WAT, $38.0 \pm 4.0 \%(n=938)$ of the grafted $\mathrm{EYFP}^{+}$cells were found in the SCWM. Of these, $19.0 \pm 3.2 \%$ were $\mathrm{Ki}^{+}{ }^{+}$(Fig. S3B) and $29.0 \pm 4.2 \%$ expressed the oligodendrocyte marker O4 (data not shown). Furthermore, $26.0 \pm 2.0 \%$ of the $\mathrm{EYFP}^{+}$cells expressed markers for mature oligodendrocytes, such as CNP (Fig. S3C) and MBP (data not shown). Finally, $8.0 \pm 1.2 \%$ of the EYFP ${ }^{+}$ cells expressed the astroglial marker GFAP (Fig. S3D). We never found graft-derived $\mathrm{EYFP}^{+} / \mathrm{NeuN}^{+}$neurons in the SCWM (data not shown).

\section{$\mathrm{NG} 2{ }^{+}$cells purified from distinct brain areas exhibit} differential migration and lineage potential after grafting To determine whether $\mathrm{NG}_{2}{ }^{+}$cells isolated from different brain areas displayed distinct migratory and lineage potentials, we FACS purified and transplanted $\mathrm{NG}^{+} / \mathrm{EYFP}^{+}$cells from the striatal-SVZ, cerebral cortex, $\mathrm{OB}$, and cerebellum. Cells were isolated from $\mathrm{P} 6-\mathrm{P} 8$ donors to allow accurate microdissection of the tissues. After FACS purification, cells were transplanted into the LV of P3-P4 mouse brains, which were analyzed at 4 DAT to (1) define the extent of migration of the grafted cells and (2) quantify the percentage of total grafted cells found in different brain regions.

Striatal-SVZ NG2 ${ }^{+} / \mathrm{EYFP}^{+}$cells migrated both rostrally and caudally to the OB and to the SCWM (Fig. 9A1). Cells derived from SVZ NG2 ${ }^{+} / \mathrm{EYFP}^{+}$progenitors were also found in the striatum. In contrast, cells derived from $\mathrm{OB} \mathrm{NG} 2{ }^{+} / \mathrm{EYFP}^{+}$progenitors displayed a more restricted migratory potential, because a larger percentage of these cells were found in the fimbria (Fig. 9B1). Finally, cortical (Fig. 9C1) and cerebellar (data not shown) $\mathrm{NG}^{+} / \mathrm{EYFP}^{+}$progenitors did not migrate rostrally and altogether exhibited a very limited migration potential. Most of the 
cortical and cerebellar EYFP ${ }^{+}$cells were found close to the injection site and in the fimbria and striatum (Fig. 9C1) (data not shown). Figure 9A2-C2 shows quantitative data of graft-derived $\mathrm{EYFP}^{+}$cells found in different regions of the brain at 4 DAT. Significant percentages of EYFP ${ }^{+}$ cells were found in the hippocampus (6\%), RMS (15\%), and OB (18\%) only after transplantation of SVZ NG2 ${ }^{+} / \mathrm{EYFP}^{+}$ cells (Fig. 9A2,B2). In contrast, SVZ, OB, and cortical $\mathrm{NG}^{+} / \mathrm{EYFP}^{+}$cells migrated to the SCWM to a similar extent (Fig. 9A2-C2). Grafted OB NG2 ${ }^{+} / \mathrm{EYFP}^{+}$cells were found in the RMS (perhaps because of some $\mathrm{NG}^{+} / \mathrm{EYFP}^{+}$cell contamination from the RMS itself) and within the OB; however, only very rarely were they observed in the hippocampus. The percentage of graft-derived cells found in the fimbria was inversely proportional to the migratory potential of the different $\mathrm{NG}^{+} / \mathrm{EYFP}^{+}$cell populations (Fig. 9A2-C2).

The $\mathrm{OB}$ cells derived from SVZ NG2 ${ }^{+}$/ $\mathrm{EYFP}^{+}$cells were either interneurons, based on DLX/NeuN or synaptophysin/ NeuN (Fig. 9D,E) and GAD-67 expression (data not shown), or $\mathrm{O}^{+} / \mathrm{CNP}^{+}$oligodendrocytes (Fig. 9F) (data not shown). Cortical $\mathrm{NG}^{+} / \mathrm{EYFP}^{+}$cells predominantly generated $\mathrm{CNP}^{+}$viable oligodendrocytes in the SCWM (Fig. 9G) and in the striatum and fimbria (data not shown).

Altogether, these data indicate that striatal-SVZ, OB, and cortical NG ${ }^{+}$cells possess distinct migratory and lineage potentials after transplantation into the perinatal brain.

\section{Discussion}

To design future strategies aimed at brain regeneration and repair, it is of central importance to study the cellular and developmental properties of neural precursors of the SVZ. This brain area represents a source of neurons and glia from progenitor cells that maintain their cell-cycling potential throughout postnatal development into adulthood (Levison and Goldman, 1993; Zerlin et al., 1995; Lim et al., 1997; Coskun and Luskin, 2002). The identity and cellular properties of the neural stem cells in the SVZ have been studied extensively (Doetsch et al., 1999, 2002; Capela and Temple, 2002; Aguirre et al., 2004); however, the identification of common progenitors that give rise to different classes of neurons and glia in vivo is still incomplete, particularly in the early postnatal brain.

In the present study, we provide direct evidence that NG2expressing progenitor $\left(\mathrm{NG}^{+}{ }^{+}\right.$) cells of the SVZ can generate GABAergic interneurons and oligodendrocytes in the postnatal OB. We used two distinct transgenic mice, the CNP-EGFP (Yuan et al., 2002) and the $\beta$-actin-EYFP mouse (Tg ActbEYFP; stock number 003772), to identify $\mathrm{NG} 2^{+}$cells and their differentiated progeny in vivo and in vitro. We obtained identical results from both transgenic animals. Our findings in the early postnatal brain indicate the following: (1) the $\mathrm{OB}$ contains interneurons and oligodendrocytes that express CNP-EGFP; (2) the RMS contains
$\mathrm{EGFP}^{+}$cells that display properties of committed neuronal $\left(\mathrm{DC}^{+}\right.$and $\left.\mathrm{Er} 81^{+}\right)$or oligodendrocyte $\left(\mathrm{NKx} 2.2^{+}\right)$progenitors; (3) DiI injection into the $\mathrm{LV}$ results in the labeling of $\mathrm{NG}^{+} / \mathrm{DiI}^{+}$ progenitors that migrate rostrally and caudally to the $\mathrm{OB}$ and the SCWM, respectively; (4) $\mathrm{NG}^{+} / \mathrm{EYFP}^{+}$and NG2 ${ }^{+} / \mathrm{EGFP}^{+} \mathrm{pro}^{-}$ genitor cells transplanted into the LV reproduced the same pattern of migration of endogenous $\mathrm{NG}_{2}{ }^{+} / \mathrm{DiI}^{+}$cells and generated interneurons and oligodendrocytes in the OB; and (5) clonally expanded $\mathrm{NG}^{+}$cells purified from the SVZ generated $\mathrm{OB}$ GABAergic interneurons and oligodendrocytes in vitro.

We have demonstrated recently (Aguirre et al., 2004) that early postnatal NG2 ${ }^{+}$cells that also express the CNP gene in the SVZ display cellular properties described previously for adult type-C cells (Doetsch et al., 1999, 2002; Capela and Temple, 2002) and generate GABAergic interneurons in the postnatal hippocampus (Belachew et al., 2003; Aguirre et al., 2004). We have also shown that $\mathrm{NG}_{2}{ }^{+}$cells self-renew and express different markers of postnatal/adult neural stem cells, including LeX (Capela and Temple, 2002), the EGF-R (Doetsch et al., 2002), PSA-NCAM (Nguyen et al., 2003), and the transcription factors Olig2, Mash1, and DLX (Doetsch et al., 2002; Doetsch, 2003). In the present study, we demonstrated that the $\mathrm{OB}$ interneuron marker Er81 and the neuroblast marker DC (Parmar et al., 2003; Stenman et al., 2003) are also expressed by a significant percentage of SVZ NG2 ${ }^{+}$cells, indicating a possible lineage relationship between $\mathrm{NG} 2{ }^{+}$progenitors and $\mathrm{OB}$ interneurons. This relationship is directly demonstrated by our results obtained by DiI 

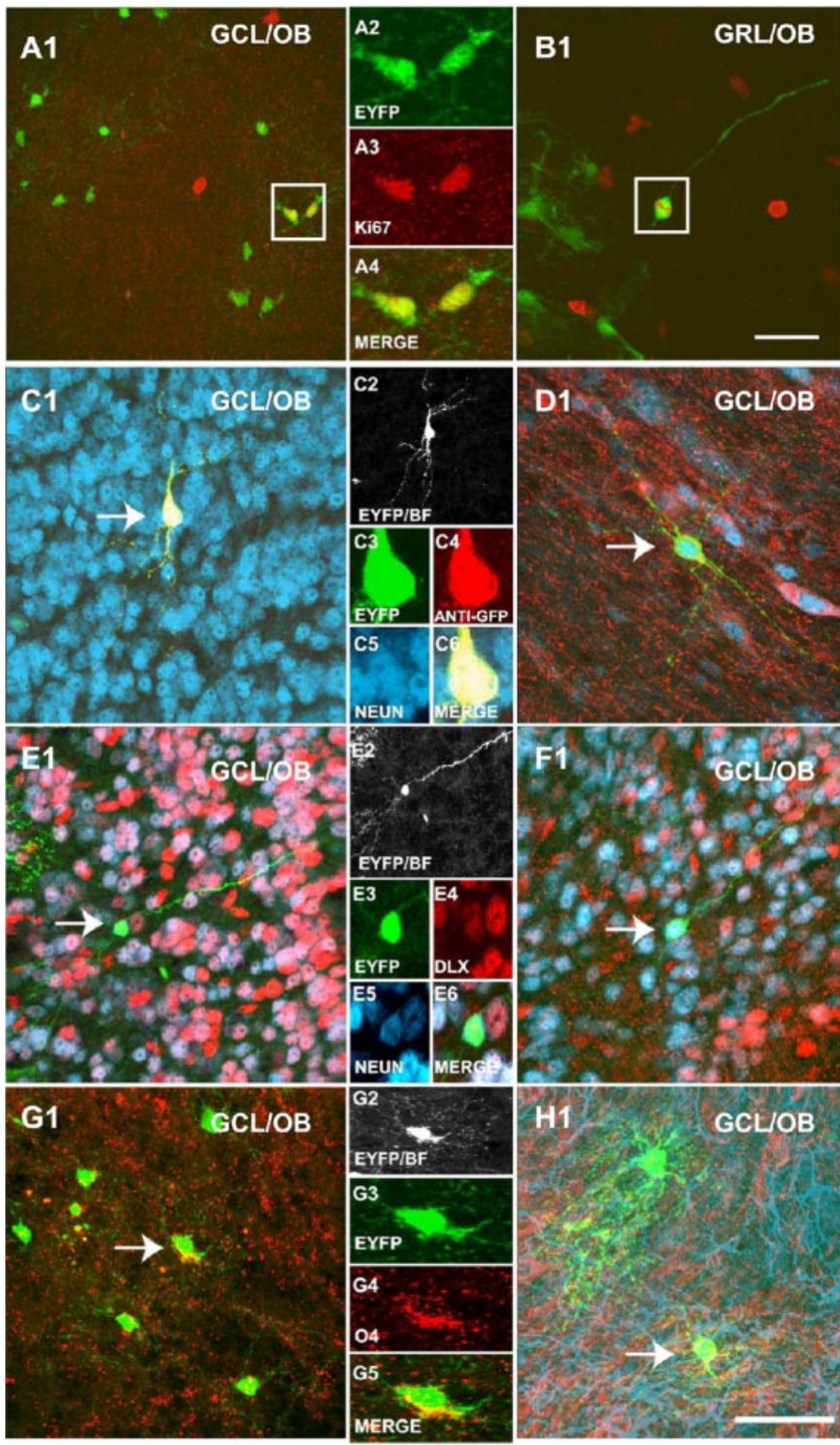

Figure 8. Grafted NG2 ${ }^{+} / \mathrm{EYFP}^{+}$cells differentiate into region-specific interneurons and mature oligodendrocytes in the $\mathrm{OB}$. Tissue analysis was performed at 3 WAT. $A, B$, A significant percentage of grafted EYFP ${ }^{+}$cells are still proliferative in the $0 B$, as demonstrated by Ki67 staining ( $A 3, B 3$; red). $C-F$, Grafted EYFP ${ }^{+}$cells display mature $0 B$ interneuron markers. EYFP ${ }^{+}$cells were stained with anti-NeuN ( $(5, D 5, E 5, F 5$; blue), anti-GAD-67 (D4; red), anti-Dlx (E4; red), and anti-Er81 (F4; red). Tissue was also processed for immunohistochemistry with anti-GFP (C4; red) to confirm the identity of graft-derived cells. G1-G5, Grafted EYFP ${ }^{+}$ cells were labeled with the oligodendrocyte marker 04 (G4; red). $\mathrm{H1}-\mathrm{H6}$, Grafted EYFP ${ }^{+}$cells also displayed a mature oligodendrocyte phenotype, based on CNP protein expression ( $H 4$; red) and absence of GFAP (H5; blue). In $22, \mathrm{D2}$, E2, F2, G2, and H2, EYFP expression was color converted to black and white to show the full morphology of the grafted cells. The boxes in $A 1$ and $B 1$ are shown at a higher magnification in $A 2-A 4$ and $B 2-B 4$. Arrows indicate cells shown at higher magnification. Scale bars, $50 \mu \mathrm{m}$.

labeling of SVZ cells and by grafting of FACS-purified NG2 ${ }^{+}$cells. With these approaches, we demonstrate that, with a similar time course of a few days, both endogenous and transplanted NG2 ${ }^{+}$cells migrate from the SVZ into the RMS to generate OB interneurons and oligodendrocytes.

In the SVZ, endogenous $\mathrm{DC}^{+} / \mathrm{EGFP}^{+}$progenitors are either $\mathrm{NG}^{+}$or NG2 ${ }^{-}$, but in the RMS, the vast majority of the endogenous $\mathrm{DC}^{+} / \mathrm{EGFP}^{+}$cells are $\mathrm{NG}^{-}$, indicating that NG2 expression might be downregulated while progenitors migrate from the

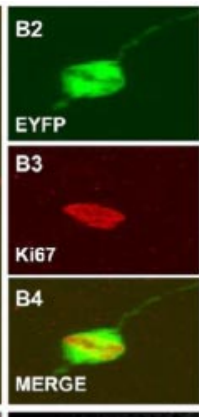

D2
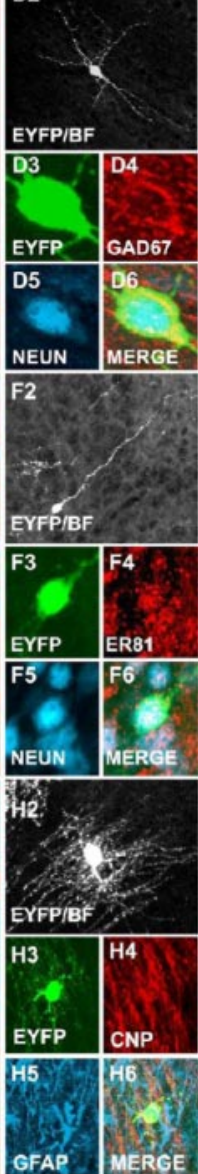

SVZ into the RMS. This hypothesis is consistent with (1) the previous finding that NG2 expression is downregulated in endogenous and grafted progenitors when they differentiate to GABAergic interneurons in the postnatal hippocampus (Belachew et al., 2003; Aguirre et al., 2004) and (2) the grafting experiments performed in the present study with $\mathrm{NG}^{+} / \mathrm{EYFP}^{+}$ cells, which demonstrate downregulation of NG2 expression in $\mathrm{EYFP}^{+}$cells that migrate into the RMS.

We FACS purified NG2-expressing progenitors from two distinct transgenic mouse strains (CNP-EGFP and $\beta$-actinEYFP mice) to circumvent possible artifacts attributable to changes in the cellular properties of the progenitor population, which might be caused by promoter activity. Our data clearly indicate that both $\mathrm{NG}^{+} / \mathrm{EGFP}^{+}$and $\mathrm{NG}^{+} / \mathrm{EYFP}^{+}$progenitors migrated from the SVZ into the RMS and generated $\mathrm{OB}$ interneurons within 2 weeks after transplantation. The neuronal differentiation potential of $\mathrm{NG} 2{ }^{+}$progenitors is linked to the expression of the $\mathrm{OB}$ region-specific gene Er81 and the neuroblast markers DLX and DC, which are present in a significant percentage of $\mathrm{NG}^{+}$cells in the SVZ and in the RMS and are maintained in their differentiated progeny in the OB. These results are strongly in agreement with the fatemapping studies performed by Stenman et al. (2003) in the Dlx5/6-cre transgenic mouse, which demonstrated that Er81expressing cells in the GCL and GRL of the OB derive from progenitors of the SVZ that express DLX.

Based on the finding that postnatal $\mathrm{NG} 2{ }^{+}$cells share molecular and cellular properties of adult type-C cells of the SVZ (Doestch et al., 2002; Aguirre et al., 2004), it is plausible that both oligodendrocytes as well as interneurons of the OB could derive from $\mathrm{NG}^{+} / \mathrm{EGFP}^{+}$progenitors of the SVZ. In support of this hypothesis, we found that a significant percentage of $\mathrm{NG}_{2}{ }^{+} / \mathrm{EGFP}^{+}$cells in the aSVZ and RMS expressed Nkx2.2, a cellular marker for OPs (Ericson et al., 1997), and many $\mathrm{EGFP}^{+}$cells in the $\mathrm{OB}$ expressed the oligodendrocyte marker CNP protein. Furthermore, transplantation of FACSpurified $\mathrm{NG}_{2}{ }^{+}$progenitors resulted in the generation of oligodendrocytes in the $\mathrm{OB}$ as early as 2 weeks after grafting. The finding that Nkx2.2 and Er81 were not coexpressed in EGFP progenitors of the RMS or coexpressed in a very small percentage of $\mathrm{EGFP}^{+}$cells of the aSVZ (Table 1 ) indicates that $\mathrm{NG}^{+} / \mathrm{EGFP}^{+} /$ $\mathrm{Nkx} 2.2^{+}$and $\mathrm{NG}^{+} / \mathrm{EGFP}^{+} / \mathrm{Er} 81^{+}$cells represent two distinct $\mathrm{NG} 2^{+}$progenitor subpopulations. This is confirmed by the observation that in FACS-purified SVZ NG2 ${ }^{+} / \mathrm{EGFP}^{+}$cells, only $5 \%$ of the cells coexpressed Nkx2.2 and Er81 (data not shown). 
Table 2. Cellular characterization of $\mathrm{EYFP}^{+}$cells of the $\mathrm{OB}$ derived from transplanted NG2 ${ }^{+} /$EYFP $^{+}$cells

\begin{tabular}{llrr}
\hline & \multicolumn{4}{l}{ Percentage of total $\mathrm{EYFP}^{+}$in the OB } \\
\cline { 2 - 4 } & $\mathrm{NeuN}^{+}$ & \multicolumn{1}{c}{$04^{+}$} & $\mathrm{NI}$ \\
\hline $\mathrm{GCL}$ & $19 \pm 1$ & $52 \pm 2$ & $10 \pm 2$ \\
$\mathrm{GRL}$ & $10 \pm 2$ & $5 \pm 2$ & $3 \pm 1$ \\
\hline
\end{tabular}

Percentages of EYFP ${ }^{+}$cells expressing NeuN and 04 were estimated by scoring the number of cells double-labeled with the marker in question. Numbers indicate the mean and SEM of numbers of EYFP ${ }^{+}$cells found in each region of the 0 B. Cell numbers were obtained from three different experiments ( 3 brains total), as described in Table 1 and in Materials and Methods. EYFP ${ }^{+}$cells were counted in the GCL and GRL of the OB. Total EYFP ${ }^{+}$cells counted ranged between 7530 and 8760 . NI, Unidentified by either NeuN or 04 antibodies. Cell counting data in tissue sections are expressed as averages \pm SEM
Abundant oligodendrogenesis from $\mathrm{NG}^{+}$progenitors was also observed in the SCWM within a few days after grafting in the LV. However, in the same brain area, we also found a significant percentage of $\mathrm{GFAP}^{+}$astrocytes derived from transplanted $\mathrm{NG}_{2}{ }^{+}$progenitors. These results are consistent with previous data demonstrating that $\mathrm{A} 2 \mathrm{~B} 5^{+}$progenitors isolated from the human fetal brain and transplanted into the white matter of shiverer mice gave rise to both oligodendrocytes and astrocytes (Windrem et al., 2004).

OB oligodendrogenesis from SVZ progenitors has been studied previously in different experimental models of demyelination (Vitry et al., 2001; Picard-Riera et al., 2002). In these animal models, it was demonstrated that SVZ progenitor proliferation and migration into the RMS was enhanced in response to experimental autoimmune encephalomyelitis (EAE) or in the shiverer mouse. This resulted in a significant increase in oligodendrocyte number in the OB (Vitry et al., 2001; Picard-Riera et al., 2002). Importantly, the SVZ progenitor population recruited for new oligodendrocyte formation was characterized as being PSA-NCAM ${ }^{+} / \mathrm{NG}^{+}$ or PSA-NCAM ${ }^{+}$in the EAE (Picard-Riera et al., 2002) or shiverer (Vitry et al., 2001) model, respectively. These properties are consistent with our finding that $\mathrm{NG}_{2}{ }^{+}$/ $\mathrm{EGFP}^{+}$cells in the postnatal SVZ also express PSA-NCAM (Aguirre et al., 2004), although our data indicate that SVZ $\mathrm{NG}_{2}{ }^{+}$cells also contribute to postnatal oligodendrogenesis in the OB under nonpathological conditions.

Our study indicates that both endogenous and transplanted $\mathrm{NG}^{+} / \mathrm{EGFP}^{+}$or $\mathrm{NG}^{+} / \mathrm{EYFP}^{+}$progenitors migrate both rostrally into the RMS and caudally to the SCWM. Rostral migration of neuronal progenitors from the adult SVZ through the RMS to the OB has been widely described (Coskun and Luskin, 2002; Carleton et al., 2003; Suzuki and Goldman, 2003); however, whether OPs could also display the same migration pattern has not been determined. Our analysis in the early postnatal brain demonstrates that endogenous and transplanted $\mathrm{NG}^{+} / \mathrm{Nkx} 2.2^{+}$ OPs can migrate through the RMS, as shown previously for $\mathrm{NG}^{+} / \mathrm{PSA}-$ $\mathrm{NCAM}^{+}$SVZ progenitors in EAE mice (Picard-Riera et al., 2002). The validity of these findings is corroborated by the results obtained in the same experiments, which demonstrated that both endogenous $\mathrm{NG}^{+} / \mathrm{EGFP}^{+} / \mathrm{DiI}^{+}$progenitors and transplanted $\mathrm{NG}^{+} / \mathrm{EYFP}^{+}$cells migrated caudally to the SCWM to generate oligodendrocytes. Caudal migration of OPs to the SCWM has been defined previously by using retroviral injection in the SVZ (Zerlin et al., 2004). Our data ob-

tained with different approaches support
Figure 9. Distinct migratory and lineage potential of $\mathrm{NG}^{+}$cells isolated from different brain regions. A1-C1, Forebrain diagrams showing representative cellular distributions of striatal-SVZ (A1), OB (B1), and cortical (C1) NG2 ${ }^{+} /$EYFP ${ }^{+} 4 \mathrm{~d}$ after grafting in the LV. A2-C2, Pies representing the percentages of total grafted cells found in the striatum (purple), SCWM (brown), fimbria (yellow), RMS (blue), OB (orange), and hippocampus (pink) at 4 DAT. D, E, Representative immunohistochemical characterization of $\mathrm{LLX}^{+}(D 3 ;$ red $) / \mathrm{NeuN}^{+}(D 4 ;$ blue $)$ or synaptophysin ${ }^{+}$(SYNAP;E3, red)/NeuN ${ }^{+}$(E4; blue) $0 \mathrm{~B}$ neurons derived from grafted SVZ NG2 ${ }^{+} /$EYFP $^{+}$cells. F, Representative immunohistochemical characterization of an oligodendrocyte derived from SVZ NG2 ${ }^{+} /$EYFP $^{+}$cells in the OB stained with 04 antibodies (F3; red). G, Representative immunohistochemical characterization of an oligodendrocyte derived from cortical NG2 ${ }^{+} /$EYFP ${ }^{+}$cells in the SCWM stained with anti-CNP antibodies (G3; red). Scale bar, $50 \mu \mathrm{m}$.

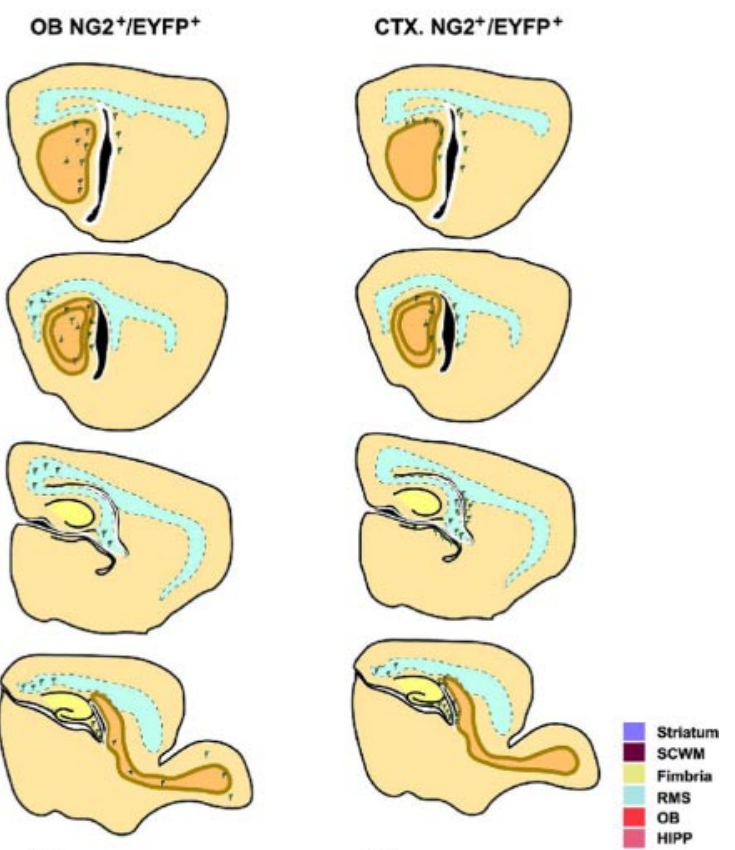


the notion that this is a major migratory pathway of SVZ progenitors that populate the SCWM to generate oligodendrocytes and astrocytes.

To determine whether $\mathrm{NG}_{2}{ }^{+}$cells of the SVZ were the direct precursors of both interneurons and oligodendrocytes in the $\mathrm{OB}$, we selectively purified these cells from the SVZ of the $\beta$-actinEYFP mouse (1) to analyze their migration pattern and lineage potential after transplantation and (2) to compare their migration pattern and differentiation with other $\mathrm{NG}^{+}$cell populations isolated from other brain regions. This analysis confirmed that $\mathrm{NG}^{+}{ }^{+}$progenitors of the SVZ extensively migrate rostrally and caudally and generate neurons and oligodendrocytes in the OB but only oligodendrocytes and astrocytes in the SCWM. Importantly, OB, cortical, and cerebellar $\mathrm{NG}^{+}{ }^{+}$cells displayed markedly distinct intrinsic properties in vivo (i.e., limited migration and a predominantly glial fate), although cortical NG2 ${ }^{+}$cells can generate neurons in culture (Chittajallu et al., 2004).

In conclusion, our data demonstrate that the early postnatal aSVZ contains distinct $\mathrm{NG}^{+}$cell subpopulations, including $\mathrm{NG}_{2}{ }^{+} / \mathrm{Er} 81^{+} / \mathrm{Dlx}{ }^{+} / \mathrm{DC}^{+}$and $\mathrm{NG} 2^{+} / \mathrm{Nkx} 2.2^{+}$progenitors. Both subpopulations migrate through the RMS and contribute significantly to neurogenesis and gliogenesis in the OB. Future experiments will further define the heterogeneity of $\mathrm{NG}_{2}{ }^{+}$progenitors located in different regions of the postnatal and adult brain in terms of their molecular and functional properties and their migration potential.

\section{References}

Aguirre AA, Chittajallu R, Belachew S, Gallo V (2004) NG2-expressing cells in the subventricular zone are type $\mathrm{C}$-like cells and contribute to interneuron generation in the postnatal hippocampus. J Cell Biol 165:575-589.

Belachew S, Chittajallu R, Aguirre AA, Yuan X, Kirby M, Anderson S, Gallo V (2003) Postnatal NG2 proteoglycan-expressing progenitor cells are intrinsically multipotent and generate functional neurons. J Cell Biol 161:169-186.

Capela A, Temple S (2002) LeX/ssea-1 is expressed by adult mouse CNS stem cells, identifying them as nonependymal. Neuron 35:865-875.

Carleton A, Petreanu LT, Lansford R, Alvarez-Buylla A, Lledo PM (2003) Becoming a new neuron in the adult olfactory bulb. Nat Neurosci 6:507-518.

Chittajallu R, Aguirre AA, Gallo V (2004) NG2-positive cells in the white and grey matter display distinct physiological properties. J Physiol (Lond), in press.

Coskun V, Luskin MB (2002) Intrinsic and extrinsic regulation of the proliferation and differentiation of cells in the rodent rostral migratory stream. J Neurosci Res 69:795-802.

Doetsch F (2003) A niche for adult neural stem cells. Curr Opin Genet Dev 13:543-550.

Doetsch F, Caille I, Lim DA, Garcia-Verdugo JM, Alvarez-Buylla A (1999) Subventricular zone astrocytes are neural stem cells in the adult mammalian brain. Cell 97:703-716.

Doetsch F, Petreanu L, Caille I, Garcia-Verdugo JM, Alvarez-Buylla A (2002) EGF converts transit-amplifying neurogenic precursors in the adult brain into multipotent stem cells. Neuron 36:1021-1034.

Ericson J, Rashbass P, Schedl A, Brenner-Morton S, Kawakami A, van Heyningen V, Jessell TM, Briscoe J (1997) Pax6 controls progenitor cell identity and neuronal fate in response to graded Shh signaling. Cell 90:169-180.

Goldman JE (1995) Lineage, migration, and fate determination of postnatal subventricular zone cells in the mammalian CNS. J Neurooncol 24:61-64.
Gritti A, Bonfanti L, Doetsch F, Caille I, Alvarez-Buylla A, Lim DA, Galli R, Verdugo JM, Herrera DG, Vescovi AL (2002) Multipotent neural stem cells reside into the rostral extension and olfactory bulb of adult rodents. J Neurosci 22:437-445.

Levison SW, Goldman JE (1993) Both oligodendrocytes and astrocytes develop from progenitors in the subventricular zone of postnatal rat forebrain. Neuron 10:201-212.

Lim DA, Fishell GJ, Alvarez-Buylla A (1997) A postnatal mouse subventricular zone neuronal precursors can migrate and differentiate within multiple levels of the developing neuraxis. Proc Natl Acad Sci USA 94:14832-14836.

Marshall CA, Goldman JE (2002) Subpallial dlx2-expressing cells give rise to astrocytes and oligodendrocytes in the cerebral cortex and white matter. J Neurosci 22:9821-9830.

Nait-Oumesmar B, Decker L, Lachapelle F, Avellana-Adalid V, Bachelin C, Van Evercooren AB (1999) Progenitor cells of the adult mouse subventricular zone proliferate, migrate and differentiate into oligodendrocytes after demyelination. Eur J Neurosci 11:4357-4366.

Nguyen L, Rigo JM, Malgrange B, Moonen G, Belachew S (2003) Untangling the functional potential of PSA-NCAM-expressing cells in CNS development and brain repair strategies. Curr Med Chem 10:2185-2196.

Parmar M, Skogh C, Englund U (2003) A transplantation study of expanded human embryonic forebrain precursors: evidence for selection of a specific progenitor population. Mol Cell Neurosci 23:531-543.

Picard-Riera N, Decker L, Delarasse C, Goude K, Nait-Oumesmar B, Liblau R, Pham-Dinh D, Evercooren AB (2002) Experimental autoimmune encephalomyelitis mobilizes neural progenitors from the subventricular zone to undergo oligodendrogenesis in adult mice. Proc Natl Acad Sci USA 99:13211-13216.

Reynolds BA, Weiss S (1992) Generation of neurons and astrocytes from isolated cells of the adult mammalian central nervous system. Science 255:1707-1710.

Spassky N, Heydon K, Mangatal A, Jankovski A, Olivier C, Queraud-Lesaux F, Goujet-Zalc C, Thomas JL, Zalc B (2001) Sonic hedgehog-dependent emergence of oligodendrocytes in the telencephalon: evidence for a source of oligodendrocytes in the olfactory bulb that is independent of PDGFRalpha signaling. Development 128:4993-5004.

Stenman J, Toresson H, Campbell K (2003) Identification of two distinct progenitor populations in the lateral ganglionic eminence: implications for striatal and olfactory bulb neurogenesis. J Neurosci 23:167-174.

Suzuki SO, Goldman JE (2003) Multiple cell populations in the early postnatal subventricular zone take distinct migratory pathways: a dynamic study of glial and neuronal progenitor migration. J Neurosci 23:4240-4250.

Temple S (2001) The development of neural stem cells. Nature 414:112-117.

Vitry S, Avellana-Adalid V, Lachapelle F, Evercooren AB (2001) Migration and multipotentiality of PSA-NCAM+ neural precursors transplanted in the developing brain. Mol Cell Neurosci 17:983-1000.

Windrem MS, Nunes MC, Rashbaum WK, Schwartz TH, Goodman RA, McKhann II G, Roy NS, Goldman SA (2004) Fetal and adult human oligodendrocyte progenitor cell isolates myelinate the congenitally dysmyelinated brain. Nat Med 10:93-97.

Yuan X, Chittajallu R, Belachew S, Anderson S, McBain CJ, Gallo V (2002) Expression of the green fluorescent protein in the oligodendrocyte lineage: a transgenic mouse for developmental and physiological studies. J Neurosci Res 70:529-545.

Zerlin M, Levison SW, Goldman JE (1995) Early patterns of migration, morphogenesis, and intermediate filament expression of subventricular zone cells in the postnatal rat forebrain. J Neurosci 15:7238-7249.

Zerlin M, Milosevic A, Goldman JE (2004) Glial progenitors of the neonatal subventricular zone differentiate asynchronously, leading to spatial dispersion of glial clones and to the persistence of immature glia in the adult mammalian CNS. Dev Biol 270:200-213. 